OPEN ACCESS

Edited by:

Chuanlong Zhu,

Nanjing Medical University, China

Reviewed by:

Qingfeng Tang,

Putuo District Central Hospital, China

Zhengyi Jiang,

Nanjing Medical University, China

Xia Liu,

Baylor College of Medicine,

United States

*Correspondence:

Yingping Wu

yingpingwu@zju.edu.cn

Jue Xie

zyyyxj2011@zju.edu.cn

Specialty section:

This article was submitted to Infectious Diseases - Surveillance,

Prevention and Treatment,

a section of the journal

Frontiers in Medicine

Received: 06 August 2021

Accepted: 31 August 2021

Published: 30 September 2021

Citation:

Cui D, Li W, Jiang D, Wu J, Xie J and Wu Y (2021) Advances in Multi-Omics

Applications in HBV-Associated

Hepatocellular Carcinoma.

Front. Med. 8:754709.

doi: 10.3389/fmed.2021.754709

\section{Advances in Multi-Omics Applications in HBV-Associated Hepatocellular Carcinoma}

\author{
Dawei Cui ${ }^{1}$, Wei $L_{i}{ }^{2}$, Daixi Jiang ${ }^{3}$, Jianguo $W u^{4}$, Jue $X i e^{1 *}$ and Yingping $W u^{4 *}$ \\ ${ }^{1}$ Department of Blood Transfusion, The First Affiliated Hospital, Zhejiang University School of Medicine, Hangzhou, China, \\ ${ }^{2}$ Center of Research Laboratory, The First People's Hospital of Lianyungang, Lianyungang, China, ${ }^{3}$ State Key Laboratory for \\ Diagnosis and Treatment of Infectious Diseases, National Clinical Research Center for Infectious Diseases, Collaborative \\ Innovation Center for Diagnosis and Treatment of Infectious Diseases, The First Affiliated Hospital, Zhejiang University School \\ of Medicine, Hangzhou, China, ${ }^{4}$ Department of Laboratory Medicine, The Fourth Affiliated Hospital, Zhejiang University \\ School of Medicine, Yiwu, China
}

Hepatitis B virus (HBV) specifically infects liver cells, leading to progressive liver cirrhosis and significantly increasing the risk of hepatocellular carcinoma (HCC). The maturity of sequencing technology, improvement in bioinformatics data analysis and progress of omics technologies had improved research efficiency. The occurrence and progression of HCC are affected by multisystem and multilevel pathological changes. With the application of single-omics technologies, including genomics, transcriptomics, metabolomics and proteomics in tissue and body fluid samples, and even the novel development of multi-omics analysis on a single-cell platform, HBV-associated HCC changes can be better analyzed. The review summarizes the application of single omics and combined analysis of multi-omics data in HBV-associated HCC and proposes the importance of multi-omics analysis in the type of HCC, which provide the possibility for the precise diagnosis and therapy of HBV-associated HCC.

\footnotetext{
Keywords: hepatitis B virus, hepatocellular carcinoma, metabolomics, proteomics, genomics, transcriptome, non-coding RNA
}

\section{INTRODUCTION}

Globally, 830,180 people died of cancers in 2020, and liver cancer became the third causative factor of cancer-associated death (8.3\% of 9.9 million deaths) (1). Hepatocellular carcinoma (HCC) is the most dominant primary liver cancer, which can be caused by hepatitis B virus (HBV), hepatitis $\mathrm{C}$ virus (HCV), alcohol abuse, and so on $(2,3)$. Although acquired HBV infection has been well-controlled by vaccines, HBV remains the main cause of HCC due to nearly 300 million individuals with chronic HBV (CHB) infection worldwide (4). It is estimated that $8-20 \%$ of untreated patients with $\mathrm{CHB}$ infection will progress to liver cirrhosis within 5 years (5), and $\sim 2-8 \%$ of the patients with liver cirrhosis can be transformed into HCC (6). Persistent HBV infection or active HBV replication results in liver injury, fibrosis, cirrhosis, and liver cancer, leading to most of the end-stage liver diseases $(7,8)$. Up to one-third of patients with HBV-associated HCC will develop cirrhotic tumors (2). Additionally, inactive HBV carriers with serum alanine aminotransferase (ALT) levels in the normal range have substantial risk of HCC compared to those without $\mathrm{HBV}$ infection (9).

Nucleos(t)ide analogs (NAs) and PEG-interferon are recommended antiviral treatments in routine medicine (such as lamivudine, adefovir, dipivoxil, entecavir, and tenofovir) that can prevent 
viral replication and $\mathrm{CHB}$ progression. However, these drugs don't affect the HBV genome in the host liver cells, which has always been in the form of covalently closed circular DNA (cccDNA) (10). Additionally, HBV-associated HCC presents more chemoresistance than non-HBV tumors. Thus, current treatment regimens are not curative, and the primary objective of therapy for CHB infection is to permanently inhibit HBV replication, followed by lifelong therapy (11). Given the above limits in treatment and huge scale of HBV infection worldwide, new therapeutic strategies are necessary.

$\mathrm{CHB}$ infection is dynamic interactions among the hepatocytes, virus and immune system of the host. In recent years, significant progress has been made in genome and proteomic analysis, clinical data management, next generation sequencing data mining, machine learning and deep learning algorithms. "Omics" technologies are used to mainly detect all protein, transcripts, and metabolites for mining for available data in the biological sample. These high-throughput technologies play critical roles in describing gene and/or protein expression profiles, and their effects on HBV-associated HCC (12-14). Although many biomarkers for diagnosis and prognosis have been identified through omics analysis of HBV infection, the previous studies focus on a single aspect of the natural history of CHB. However, most studies on systematic omics are based on genomics, transcriptomics and proteomics. The integration of multi-omics data analysis is critical for providing novel insights into the transitions and molecular mechanisms in related diseases $(15,16)$.

With the technological advances of platforms, multi-omics analysis will be more crucial for molecular therapies and precision medicine. Integrative analysis of multi-omics platforms mainly relies on innovative technology platforms including genomics, metabolomics, and proteomics. Multi-omics studies have been successfully exploited to elucidate the pathogenic mechanism of infectious diseases, such as helicobacter pylori (HP)-associated gastric carcinoma (17), COVID-19 (18), and herpes simplex virus-1 (HSV-1) infection (19). The promise of the multi-omics approach has been well-described in more complex diseases, and several studies have proposed potential biomarkers for HCC using omics resources. Although "omicslevel" studies have been very useful in understanding the mechanism of HCC manifestation, few are available to integrate different omics data.

Herein, we review recent advances in multi-omics applications, including genomics, epigenetics, transcriptomics, proteomics, and metabolomics. Overall, this review will highlight the omics advances in HBV-associated HCC to provide novel insights into immunotherapies based on specific biomarkers in the future (Figure 1).

\section{EPIDEMIOLOGY}

Hepatitis B virus is a DNA virus with a partial double-stranded relaxed circular DNA genome, containing four open reading frames (ORFs) with $P$, pre-S/S, pre-C/C, and $X$ genes, and $P r e-S / S$ comprises the pre-S1, pre-S2, and $S$ genes. The $P$ region encodes
DNA polymerase and RNase $\mathrm{H}$, which is associated with virus replication. Pre- $\mathrm{C} / \mathrm{C}$ encodes hepatitis $\mathrm{B}$ core antigen ( $\mathrm{HBcAg}$ ) and hepatitis $B$ e antigen ( $\mathrm{HBeAg}$ ), and $X$ region encodes a hepatitis $\mathrm{B} \times(\mathrm{HBx})$ non-structural protein, which is involved in viral replication and oncogenic activity. A recent report showed that the HBx protein could promote the degradation of the structural maintenance of chromosome (SMC) $5 / 6$ protein complexes to increase HBV replication and indirectly proves the association with the occurrence of HCC again (20).

Mutations of the viral genome causing biological behavior changes may have crucial effects on HBV pathogenicity and are closely associated with the malignant transition of liver cancer (21). The occurrence of HBV-associated HCC is a complex process. HBV infection can promote HCC through direct or indirect mechanisms, including HBV gene integration, genomic instability, and activation of cancerassociated signaling pathways. Additionally, new insights into the mechanism of HCC-related pathway activation, including epigenetics, autophagy, exosomes, metabolism, and immune responses (22-25), are being continuously focused on. Previous studies also showed that HBV-associated HCC individuals displayed distinctive profiles including chromosomal alterations and $\beta$-catenin mutations (26). Furthermore, genetic alterations in subgroups of HCC cases were remarkably associated with HBV-DNA levels (27). Additionally, novel biomarkers, such as DNA mutations, DNA or RNA methylation, long non-coding RNAs (lncRNAs), microRNAs (miRNAs), and circular RNAs (circRNAs), are under investigation and can be considered for future clinical practice of HCC.

Thus, integrated multi-omics analysis must be performed to obtain a better understanding of the pathogenesis of HBV-associated HCC. The combined application of genomics, epigenomics, and transcriptomics to illustrate the mechanism of virus-associated carcinogenesis is required.

\section{GENOMICS CHARACTERISTICS}

In contrast to $\mathrm{HCV}, \mathrm{HBV}$ can integrate the viral genome into the host hepatocyte genome. A thorough understanding of the pathogenesis of virus-associated carcinogenesis is critical for early diagnosis, treatment and prevention of HCC. Recent advances in deep sequencing technologies including nextgeneration sequencing, nanopore sequencing, and single-cell sequencing, contribute to revealing the landscape of genetic and epigenetic changes in tumor tissues and chronic liver damage caused by hepatitis virus infection, particularly HBV (28). Persistent suppression and/or eradication of HBV/HCV can contribute to reducing the incidence of HCC, but multicentric tumors in patients often arise after viral clearance (2931). Additionally, the accumulation of viral genetic alterations negatively affects the epigenetic transformation of normal cells into cancer cells (32). NGS technologies, including whole-exome sequencing (WXS), RNA sequencing (RNA-seq), and wholegenome sequencing (WGS), form the basis of current genomics research. Therefore, vast amounts of sequencing data have been 


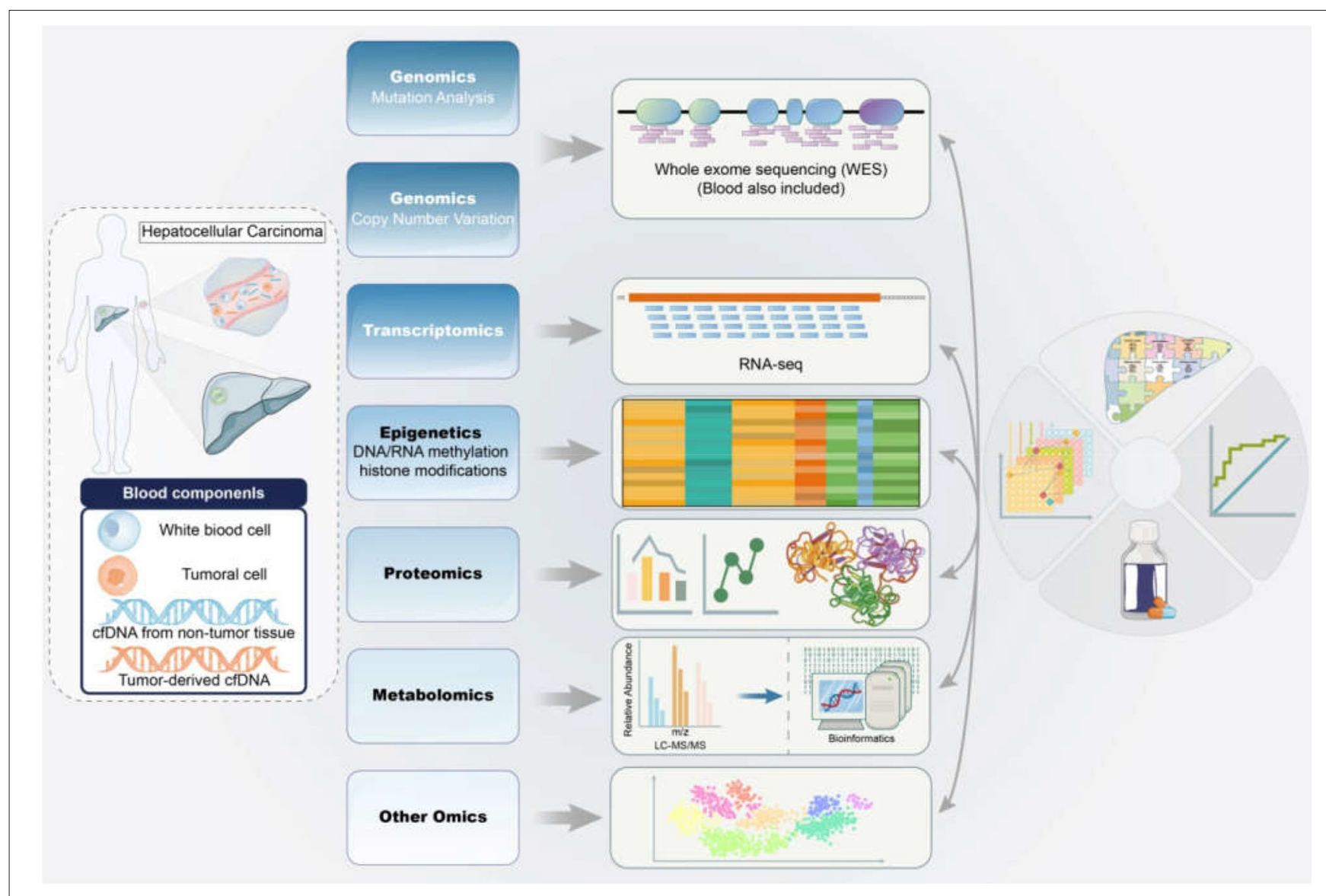

FIGURE 1 | Application of multi-omics in the diagnosis and therapy of HBV-associated HCC. The samples from HBV-associated HCC subjects were detected and analyzed by mitiomics technology including genomics, transcriptomics, epigenetics, proteomics, metabolomics and other omics to accurately promote biomarker-driven treatments and immunotherapies for HCC patients. HCC, hepatocellular carcinoma; HBV, hepatitis B virus; RNA-seq, RNA sequencing; LC-MS/MS, liquid chromatograph-mass spectrometer/mass spectrometer.

shared in global databases, allowing researchers to synthesize analyses that lead to new findings.

\section{Host Profile}

Genetic aberrations comprise nucleotide changes and structural variations (STVs) (33-35). The accumulation of somatic genomic alterations in primary tissues is the major cause of HCC. An average of 40-60 somatic alterations is detected in the protein coding regions of the genomes from HCC patients (36) (Table 1). Based on WES and single-nucleotide polymorphism (SNP) array analysis, how these mutated genes and the copy number of their alterations are involved in regulating these pivotal pathways, including cell cycle control, telomere maintenance, chromatin modification, and receptor tyrosine kinase, which have been reported (51). Among these mutations, a few genomic alterations are considered to be directly involved in the activation of the important signaling pathways for hepatocarcinogenesis.

The integration of viral genome is a unique molecular characteristic of HCC. Notably, the integration of HBV genome affects gene expression near integration sites. Multiple recurrent genetic aberrations and the disruption of the host genome due to HBV-DNA integration are important for the hallmarks of $\mathrm{HBV}$-associated HCC. By large-scale genome sequencing analysis of HCC, the core drivers (TERT, TP53, and CTNNB1/AXIN1) have been identified as initial molecular events and other low-frequency drivers including therapeutically targetable drivers. These genes regulate some pathways, including cell cycle $(p 53, p 16)$, apoptosis $(b c l 2)$, cell proliferation and differentiation (b-catenin, c-myc, APC, E-cadherin), metastasis (MMP4, MMP9, Topoisomerase, Rb, Cyclin D1, Osteopontin), angiogenesis (VEGFR-2, Angiopoietin-2), and other growth factor signaling components (IGF-II, TGF, EGFR, HGF/c-MET, PTEN, $K-R A S)(37,42)$. These findings indicate that HCC is not caused by a specific driver mutation but involves in the multiple carcinogenic pathways that enhances extremely heterogeneous of HCC.

By next-generation sequencing, somatic mutations in TP53, TERT promoter, and CTNNB1 have often been reported in HCC patients (38). Somatic mutations are abundant in TERT gene promoters and occur in more than $50 \%$ of the patients with HCC, while the protein alterations caused by gene mutations are often observed in CTNNB1 genes and TP53. Additionally, 
TABLE 1 | The common somatic genomic alterations and HBV integration events in HCC.

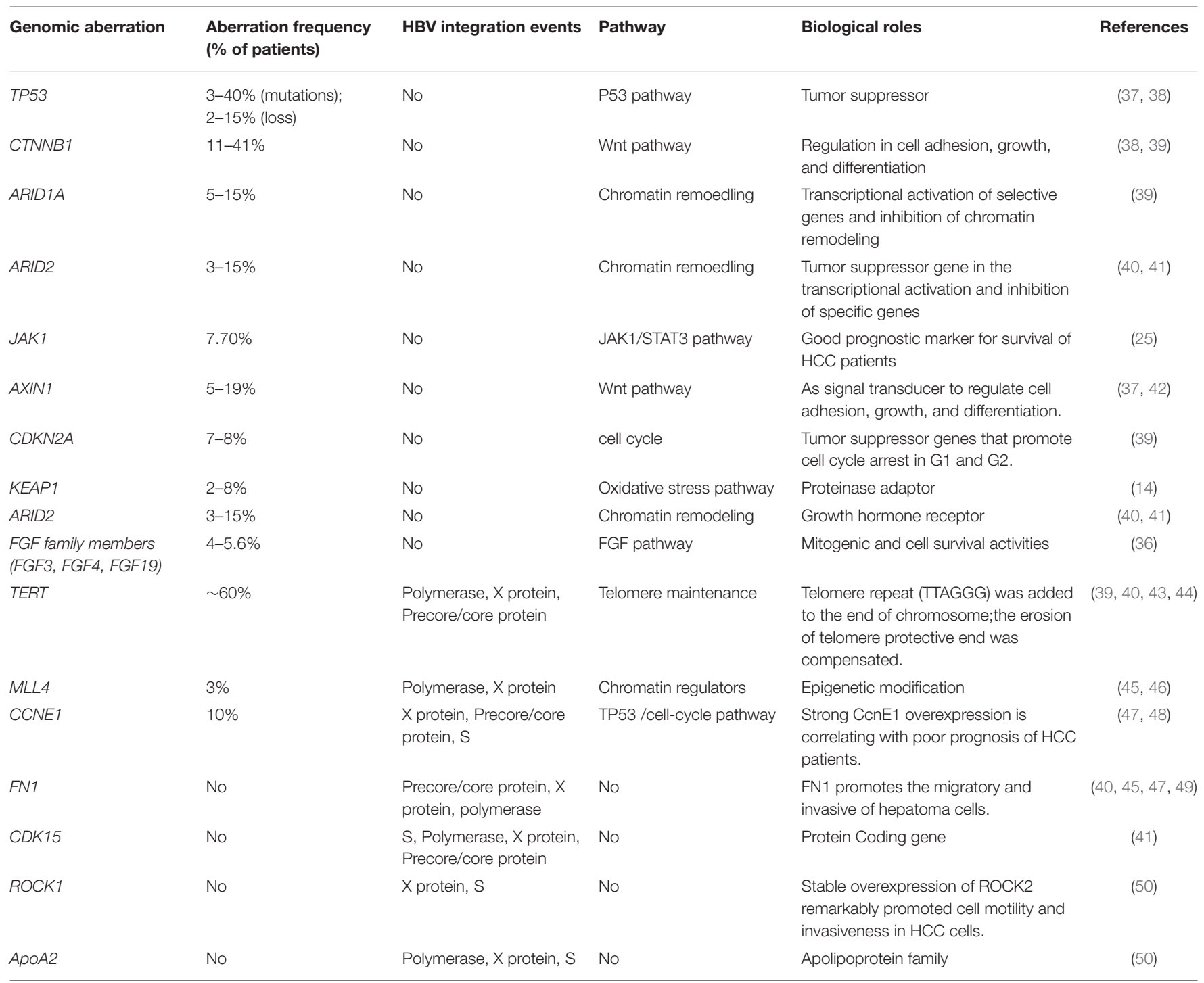

somatic structure variants (SVs) affect gene expression in cancers. The Pan-Cancer Analysis of Whole Genomes (PCAWG) Consortium revealed that $100-\mathrm{kb}$ SV breakpoints for hundreds of genes were associated with their altered expressions by aggregating whole-genome sequencing data from a cohort of 1,220 cancer individuals. For most of these genes, SVs result in increased expression rather than decreased expression, and the up-regulated cancer-related genes included TERT, CDK4, MDM2, ERBB2, PDCD1LG2, and IGF2 (39). Simultaneously, WGS analysis demonstrated several important types of SVs in the genome of liver cancer, including TERT, APC, CDKN2A, $A R I D 1 A$, and new genes such as TTC28, $L R P 1 B$, and MACROD2, and these SVs affected their expressions (39).

The increased copy number of HBV-DNA at HBV breakpoint locations indicates that chromosomal instability is associated with HBV genome integration (52). Hama et al. identified the structural rearrangement that integrated the viral genome by
WGS analysis in HBV-associated HCC (50). Therefore, the structural instability of the integrative viral genome is periodic and may be related to the chromosomal instability of the host hepatocyte genome.

\section{HBV Profile}

Approximate 350-400 million people worldwide are infected by $\mathrm{HBV}$, and persistent HBV infection leads to more than $50 \%$ of HCC patients. HBV plays an important role in the development of HCC by integrating the HBV genome into the host genome. Several high-throughput sequencing studies have reported that $\mathrm{HBV}$ genome integration occurs in a high rate of $\mathrm{HBV}$-associated HCC patients (Table 1) (52). Although HBV can randomly and repeatedly integrate into the host genome including TERT and MLL4, suggesting functional consequences for the host by HBV integration events (45). Some studies have also identified that the region between 1,600 and 1,900 nucleotides within 
the viral genome, corresponding to the $3^{\prime}$-end of $\mathrm{HBx}$ gene and $5^{\prime}$-end of precore gene, is not only preferentially involved in structural alterations within the viral genome, particularly deletion and inversion events, but also significantly related with the insertion into the host genome $(43,53)$. In a previous study, HBV genome integration was significantly enriched on the qarm of chromosome-10 in a cohort of 48 HCC cases, and the event was related with poorly differentiated tumors (43). In several studies, HBV has been reported to integrate into the CCNE1 and TERT genes. However, CDK15, ROCK1, FN1, ApoA2, and MLL4 have rarely been reported as HBV integration sites $(40,47,49)$. In 76 samples of HBV-associated HCC cases, 4 cases of HBV integration within CCNE1 were reported, resulting in the high expression of CCNE1 (47). Multiple highthroughput genomic studies have found that repeated integration sites on TERT promoters are the most frequent integration sites (40). Disruption of the telomerase reverse transcriptase (TERT) promoter may result in the dysregulation of TERT expression (44). The mRNA expression of TERT is increased when HBV binds to the TERT transcription start site, which implies HBV sequences as enhancers for TERT mRNA expression (43). In a Chinese cohort of forty-four HBV-associated HCC tissues, 8 fusion transcripts of $H B x / M L L$ were found, leading to high expression of the MLL4 gene (46). Furthermore, multiple transcripts with HBV-CDK15 fusion were observed in an HCC case, including one in-frame fusion, which induced CDK15 overexpression (41). Hence, the genes of CCNE1, ANGPT1, and $T E R T$ are not only mutated in somatic cells, but also integrated in viruses (48).

\section{EPIGENETICS CHARACTERISTICS}

Viruses can alter the chromatin structure by redirecting the modifications of chromatin and consequently affecting host cell transcription, which may contribute to oncogenesis $(54,55)$. Epigenetics refers to changes of gene expression without altering the underlying DNA sequence, and comprises three major components: histone modifications, DNA methylation, and noncoding RNA mechanisms (56). Hepatocellular carcinoma is caused by the somatic mutations leading to the abnormalities of chromatin regulations and epigenetic characteristics (57). In the cases with HBV infection, the disorders of DNA/RNA methylation and histone modifications have been reported, but which have focused on specific genes or pathways, and genomewide mapping of the epigenetic alterations is rare.

\section{DNA Methylation}

DNA methylation in many tumor suppressor genes is related with carcinogenesis. Through an array-based platform, the genomic DNA methylation pattern of nearly 200 patients with HCC further revealed the different cancer-specific DNA hypermethylation clusters (58). DNA methylation is significantly different among HCV-related HCC, HBV-associated HCC and normal tissue (Table 2) (66). However, some evidences support more prominent DNA methylation alterations in HCV-associated HCC than in HBV-associated HCC (67). Similar to other cancers, HCC is characterized by the global
DNA hypomethylation and promoter hypermethylation, which are related with the up-regulated tumor-promoting genes $(68,69)$. High frequencies of aberrant DNA hypermethylation of specific genes (GSTP1, RASSF1A, DOK1, and CHRNA3) in HCC were reported, and these genes was suggested as a prognostic marker of HCC combined with clinicopathological data $(59,60)$. Furthermore, a recurrent hypomethylated enhancer of CCAAT/enhancer-binding protein-beta (C/EBP- $\beta$ ) promoted HCC tumorigenicity through global transcriptional reprogramming (70). Methylation of the APC, RASSF1A, and GSTP-1 genes is associated with HCC (61-64). Apart from methylation at gene promoters and $\mathrm{CpG}$ islands, epigenetic regulation and genome-wide enhancer hypomethylation patterns in primary human HCCs must be elucidated by whole-genome sequencing. In HCC patients, the latest three reports identified 6 CpG sites in white blood cell (WBC) DNA and showed that DNA methylation at those sites could distinguish HCC from healthy blood in prospective samples taken before diagnosis (71-73). Additionally, compared with hepatitis and cirrhosis liver tissues, increased DNA methylation of $\mathrm{CpG}$ island 3 in the $\mathrm{HBV}$ genome indicated HBV methylation in HBV-associated HCC pathogenesis (74). Furthermore, HBV infection induces gene methylation in HCC (75). HBV infection promotes the activity of DNA methyltransferase, which causes the simultaneous methylation of host CpG islands and HBV-DNA in cell experiments (76).

However, the potential for these markers to be used for clinical application is low because biopsies are unsuitable for early diagnosis. Because blood contains circulating tumor DNA, blood may be a promising material for carrying the same DNA methylation signals of markers as tumor tissue $(71,77)$. With the important role of "liquid biopsy" in identifying specific molecular signals in nucleic acids released by cancer cells, some studies have found that by detecting the methylation level of specific sites of circulating tumor DNA(ctDNA) in a small amount $(4-5 \mathrm{ml})$ of peripheral blood, it can be used to accurately diagnose HCC early and to predict the curative effect and prognosis (78).

\section{RNA Methylation}

N6-methyladenosine (M6A) is present in most eukaryotic messenger RNAs (mRNAs) and is the most commonly modified form of mammalian RNA. Recently, some studies have reported that hepatocarcinogenesis is closely related with abnormal m6A modifications $(79,80)$. They found that high expression of the m6A methylase METTL3 in HCC patients leads to high levels of $\mathrm{m} 6 \mathrm{~A}$ in SOCS2 $\mathrm{mRNA}$, resulting in the rapid degradation of SOCS2 and HCC occurrence (79), while METTL14 had no significant effect on HCC, and down-regulation of METTL14 expression was related with a poor prognosis in HCC patients without recurrence (80). Although the relationship between DNA and RNA m6A remains unclear, at least one independent way can verify the $\mathrm{m} 6 \mathrm{~A}$ modification sites predicted by big data (81). By transcriptome sequencing, some genes related with m6A in HCC, particularly METTL3 and YTHDF2, had been confirmed to be a risk signature (79). The processing of miR-126 maturation is mediated by the methylation transferase METTL14 in HCC, and the reduced expression of miR-126 
TABLE 2 | DNA methylation in HBV-associated HCC.

\begin{tabular}{|c|c|c|c|}
\hline DNA methylation & $\begin{array}{l}\text { Methylation } \\
\text { status }\end{array}$ & Biological functions in HCC & References \\
\hline RASSF1A & Hypermethylation & $\begin{array}{l}\text { As a diagnostic and prognostic non-invasive biomarker } \\
\text { for HCC. }\end{array}$ & $(59,60)$ \\
\hline GSTP1 & Hypermethylation & $\begin{array}{l}\text { As a diagnostic marker, GSTP1 methylation can } \\
\text { obviously enhance the risk of HBV-associated HCC } \\
\text { patients with cirrhosis. }\end{array}$ & $(59-61)$ \\
\hline DOK1 & Hypermethylation & $\begin{array}{l}\text { A tumor suppressor gene, and methylation level of DOK1 } \\
\text { is inversely related with gene expression. }\end{array}$ & $(59,60)$ \\
\hline$A P C$ & Hypermethylation & $\begin{array}{l}\text { Methylation of APC could involve in early stages of } \\
\text { HBV-related HCC, coupled with RASSF1A. }\end{array}$ & $(61-65)$ \\
\hline$p 16$ & Hypermethylation & $\begin{array}{l}\text { As a diagnostic marker, P16 methylation in promoter } \\
\text { region could obviously increase the risk of } \\
\text { HBV-associated HCC in patients with cirrhosis. }\end{array}$ & $(37)$ \\
\hline MGMT & Hypomethylation & $\begin{array}{l}\text { Loss of methyl-cytosine at the MGMT gene promoter } \\
\text { may be considered as an early and transient biomarker } \\
\text { of hepatocarcinogenesis. }\end{array}$ & $(60)$ \\
\hline
\end{tabular}

maturation will cause HCC metastasis (80). Thus, regulators of $\mathrm{m} 6 \mathrm{~A}$ modification can become potential biomarkers for prognosis in $\mathrm{HBV}$-associated HCC.

\section{Histone Modifications}

In the hepatocyte nucleus, HBV-cccDNA assembles with the histone proteins of host cells to form minichromatin, which is dynamically regulated through histone post-translational modifications (PTMs) to promote the expression of viral genes. Previous reports have revealed a series of histone modifications on HBV cccDNA, such as H3K4me2, H3K4me3, H3K9ac, $\mathrm{H} 3 \mathrm{~K} 27 \mathrm{ac}, \mathrm{H} 3 \mathrm{~K} 36 \mathrm{me} 3$, and H3K9me3. H3K4me2, H3K4me3, $\mathrm{H} 3 \mathrm{~K} 9 \mathrm{ac}, \mathrm{H} 3 \mathrm{~K} 27 \mathrm{ac}$, and $\mathrm{K} 3 \mathrm{~K} 36 \mathrm{me} 3$ are associated with activating gene expression, while $\mathrm{H} 3 \mathrm{~K} 9 \mathrm{me} 3$ is related to gene silencing (82). A highly sensitive technique, 3C-high-throughput genome-wide translocation sequencing (3C-HTGTS), was used to identify the interactions of HBV-DNA and host DNA in which H3K4me1 histone modification is enriched by $\mathrm{kmt} 2 \mathrm{c} / \mathrm{d}$, while $\mathrm{H} 3 \mathrm{~K} 4 \mathrm{me} 1$ histone modification contributes to activate the transcriptional activity of HBV. They found that histone modifications not only strongly affected HBV transcription on minichromosomes of HBV cccDNA but also affected host gene expression (83). Recently, Alvarez-Astudillo et al. found that the histone variant H3.3 was assembled from the histone chaperone HIRA to the $\mathrm{HBV}$-cccDNA, and this assembly was correlated with increased levels of the active $\mathrm{H} 3 \mathrm{~K} 4 \mathrm{me}$ and activation of HBV transcription (84). The first genome-wide maps of PTMs obtained by chromatin immunoprecipitation sequencing (ChIP-Seq) have revealed that high levels of PTMs associated with transcription activation are enriched at specific sites in the HBV genome, whereas very low levels of PTMs are related with transcriptional inhibition, even at silent HBV promoters (82). Herein, the effect of transcriptional and active PTMs may open the possibility of chromatin regulating $\mathrm{HBV}-\mathrm{cccDNA}$ transcription, providing a new way to treat chronic hepatitis B virus infection.

\section{TRANSCRIPTOMICS CHARACTERISTICS}

\section{Host-HBV Transcription}

Hepatitis B virus plays a crucial role in HCC progression by integrating the viral genome into the host genome, and genome integration events are observed in $\mathrm{HBV}$-associated HCC patients using high-throughput sequencing (43, 47, 52, 85). Pregenomic RNA (pgRNA) of $3.5 \mathrm{~kb}$, an RNA intermediate, is critical for $\mathrm{HBV}$ replication. Thus, the level of HBV replication in tumors or adjacent non-tumors is assessed by the presence of intact pgRNAs in liver tissue, but few intact pgRNAs are observed, particularly in the tumor tissues of HCC patients.

Most somatic mutations in HCC are in the coding regions with potential functional effects. Five thousand four hundred and eleven tumor-specific mutations were identified with an average of 230 somatic mutations in each HCC patient, and these somatic mutations were significantly different in the distribution of the different genomic regions and their predicted functions. Moreover, deep transcriptome sequencing of HCC patients provides information on RNA expression, transcriptional mutations and characteristics of HBV-human chimeric transcripts (45). The integration characteristics of HBV were identified by RNA sequencing, and the preferred integration sites near the telomeres were reported (52). The integration sites in the structural changes within HBV and host genome have been well-described at the genomic level, but the status of HBV transcripts in HBV-associated HCC has not been comprehensively analyzed (86). To Target different HBV transcripts in depth, Stadelmayer et al. have developed an HBV full-length 5 ' RACE (rapid amplification of cDNA ends) method, which significantly contributes to the understanding of $\mathrm{HBV}$ transcription and may guide the development of new therapies targeting HBV-cccDNA (87).

HBV fusion sequences are significantly enriched on chromosome 10 (43). More HBV-human fusions (161 fusions) in non-tumorous tissues were observed in the HCC transcriptome of 22 HCC patients than in matched HCC tissues (33 fusions) 
(41). Notably, the data obtained through transcriptome analysis showed that most chimeric transcripts in tumors fuse with gene sequences more than at the genomic level, HBV was fused with the repetitive sequences, particularly the LINE and SINE families of the repetitive sequences in $40 \%$ of the chimeric transcripts (43).

Although transcriptome sequencing can provide valuable insights into the characteristics of HBV-associated HCC patients, most studies have focused on host transcripts rather than viral transcripts (88-90). More than $90 \%$ of $\mathrm{HBV}$-associated HCC contains transient HBV-DNA integration, which does not produce all the HBV antigens, and these transient HBV-DNA fragments encode epitopes that can be recognized by activate T cells (47, 91-93). The HBV transcriptomes of the HCC cells can be used for individualized immunotherapy with engineered $\mathrm{T}$ cells and as a treatment measure for a wider range of HBVassociated HCC patients (93). The transcriptome similarities and differences in $\mathrm{CD}^{+} \mathrm{T}$ cell dysfunction were explored in both chronic HBV infection and HCC patients through high-throughput RNA-seq, and the results demonstrated that $\mathrm{CD}^{+} \mathrm{T}$ cell dysfunction in the two groups shared high similar characteristics, but each had its own characteristics in specific genes and signal pathways (94).

\section{Non-coding RNA}

Non-coding RNAs (ncRNAs) are functional RNAs that cannot encode proteins. ncRNAs make up a significant proportion of cellular RNAs, accounting for more than $90 \%$ of human RNAs. Recent reports have shown that ncRNAs play an important role in multiple cellular processes including cell proliferation, apoptosis, migration, and angiogenesis. Many tumor cells including liver cancer cells, also release specific circRNAs, microRNAs (miRNAs), long non-coding RNAs (lncRNAs), and extracellular vesicles containing proteins, lipids, RNAs and miRNAs in peripheral blood (95-98). Non-coding variants are closely linked to human cancers and are even involved in drug resistance in HCC. Herein, we focused on miRNAs, lncRNAs and circRNAs implicated in the pathogenesis of HCC (Table 3).

\section{miRNAs}

miRNAs are one kind of important non-coding RNAs (ncRNAs), $\sim 22$ nucleotides in length, and are highly expressed in many types of tumors associated with HCC progression or suppression (101, 102). miRNAs may act as tumor suppressor genes or oncogenes by silencing and targeting mRNAs involved in carcinogenesis. Recent studies showed that miRNA expression is more valuable than mRNA-based profiling to identify tissue types of tumor origin, and cancer treatments targeting miRNAs are currently in clinical trials as early detection markers of HCC $(100,121)$. In the past 2 years, many reports showed that miRNAs were closely related with hepatocarcinogenesis (116). A recent study showed that miR-154 as a tumor inhibitor could suppress cell proliferation and metastasis, and the miR-154 expression was downregulated in HCC (99). Feng et al. found that lncRNA PCNAP1 promoted HBV replication by regulating miR154/PCNA/HBV-ccCDNA signal and PCNAP1/PCNA signal, which drived the growth of both $\mathrm{HBV}$-associated HCC and
HBV-free HCC (98). Some studies have considered that miRNA expressions play an important in the pathogenesis of HCC by the downregulation of miRNAs that upregulate oncogenes or the upregulated miRNAs that target tumor suppressor genes (122). In the "Expert consensus on early screening strategy for liver cancer in China," serum miRNAs as a potential diagnostic marker have made some progress. In a study of 934 subjects, including groups of healthy people, patients with $\mathrm{CHB}$, liver cirrhosis and HBVassociated liver cancer, 723 miRNAs were screened on a large scale in plasma samples. The results showed that seven specific miRNAs were selected to construct the diagnosis model of HCC and can distinguish liver cancer from healthy people (sensitivity for $83.3 \%$, specificity for $93.9 \%$ ), liver cancer from hepatitis (sensitivity for $79.1 \%$, specificity for $76.4 \%$ ), and liver cancer from liver cirrhosis (sensitivity for 75.0\%, specificity for 91.1\%) (123). At the same time, other studies have also proven that miRNAs have important value in the diagnosis of HCC, but the sensitivity and specificity of this technology must be further improved. Furthermore, the application values of miRNAs require largescale samples and multicenter clinical verification, which can be used as a supplement for individualized diagnosis.

\section{LncRNAs}

Benefiting from advances in the transcriptome sequencing, lncRNAs, transcripts more than 200 bp in length without encoding proteins, play roles in different physiological and pathological processes and affect cellular functions $(106,124)$. To date, most of lncRNAs play important roles in regulating specific cellular processes, particularly in the expressions of protein-coding genes at the epigenetic, transcriptional and post-transcriptional levels in cancer including HCC (125). Previous studies have shown that the lncRNAs MALAT1, H19, HOTAIR (HOX transcript antisense intergene RNA), HULC, and PRNCR1 are abnormally expressed in various human cancers, particularly HCC (104). LncRNAMALAT1 induces murine HCC experimentally, H19 expression is upregulated in HBV-associated HCC, HOTAIR is overexpressed in tumor tissues from HCC patients and in liver cancer cell lines, and is related with poor prognosis of HCC, $\mathrm{HBx}$ upregulates lncRNAHULC by inhibiting P18 and promoting the occurrence of $\operatorname{HCC}(103,105,107,108)$. Additionally, the up-regulated expressions of IncRNA-HEIH and HOTTIP promoted tumor progression and significantly associated with tumor progression and disease outcome in HCC patients $(109,110)$. Low expression of lncRNA-MEG3 was observed in HCC tissues and cells, and overexpression of lncRNA-MEG3 could inhibit the proliferation, migration and invasion of HCC cells (111). LncRNA Low Expression in Tumor (lncRNA-LET) and lncRNA-SRHC were generally downregulated in HCC, which was associated with hepatic invasion and abdominal metastases $(112,113)$. Exosomal miR-21 can inhibit the expression of the lncRNA-PTENp1 to promote HCC growth, miR-21 inhibitors or lncRNA-PTENp1 overexpression can weaken the role of exosomal miR-21, which indicates that PTENp1 can repress the tumorigenic properties of HCC cells (114). These findings indicate that lncRNAs play critical regulatory roles in the proliferation, migration and invasion of HCC cells. 
TABLE 3 | Non-coding RNAs in HCC.

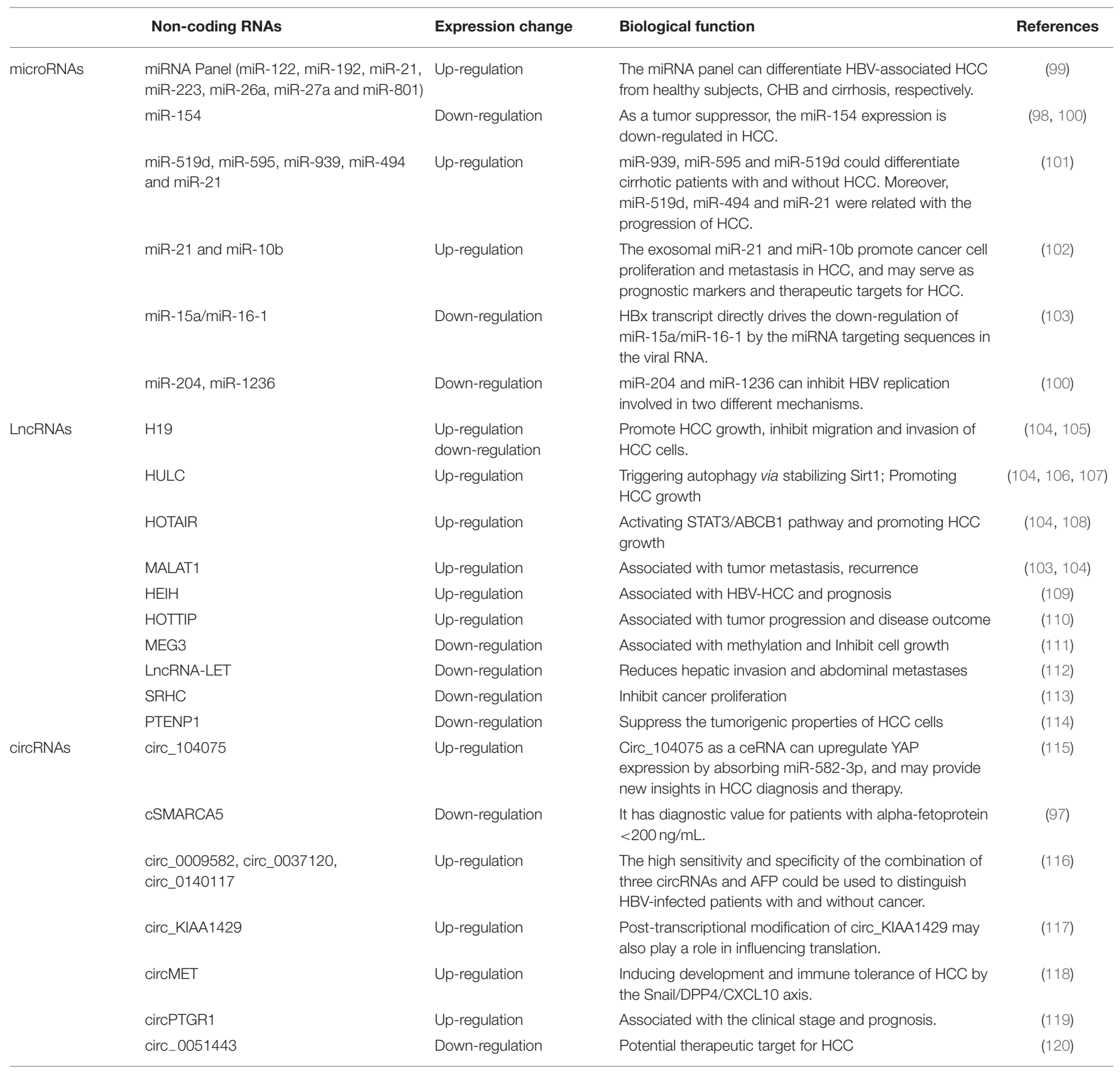

\section{CircRNAs}

CircRNAs (circular RNAs), is a new type of non-coding RNA with a closed circular structure without a $5^{\prime}$-end cap and a $3^{\prime}$ end poly A tail. Most of circRNAs are formed by exon loops encoding polypeptides, but some are lariat structures formed by intron loops without encoding ability. Currently, the biological functions of circRNAs are recognized as miRNA sponges, regulatory protein binding, regulation of gene transcription, and coding functions (126). Currently, the circRNAs in human body fluid have been identified in human disease including cancers, autoimmune diseases and infectious diseases.
For example, circ-KIAA1244 serves as a novel circulating biomarker to detect gastric cancer (115). CircRNA_0001178 and circRNA_0000826 are considered potential diagnostic biomarkers for liver metastases from colorectal cancer (117). Differential expression of circRNAs and lncRNAs is found in recurrent COVID-19 patients (118). These reports indicated that circRNAs could serve as biomarkers for the diagnosis and therapeutic intervention of human diseases.

To date, the most common mechanism by which circRNAs act as miRNA sponges and interact with certain mRNAs and miRNAs is via competing endogenous RNAs (ceRNAs) (127, 
128). RNA sequencing revealed that circRNA cSMARCA5 is downregulated in HCC, inhibiting the growth and migration of hepatocellular carcinoma cells, and is associated with a poor prognosis (97). Furthermore, $\mathrm{Wu}$ et al. reported that the combination of circ_0009582, circ_0037120, circ_0140117, and AFP has a high sensitivity and specificity to predict HCC (116). Zhang et al. reported that hsa_circ_0001445 levels in plasma are significantly downregulated, which had high specificity (94.2\%) and sensitivity (71.2\%) in HCC patients, and the efficient combination of plasma hsa_circ_0001445 and AFP levels can be used for HCC diagnosis rather than each parameter alone (129). Furthermore, another circRNA, hsa_circ_104075, was significantly increased in serum from HCC patients, and the AUC value of hsa_circ_104075 (0.973) suggested high sensitivity of $96.0 \%$ and specificity of $98.3 \%$ (119). Plasma three circRNAs (circ_0009582, circ_0037120, and circ_0140117) were overexpressed in HCC patient, and the combination of the three circRNAs and AFP acquired both valuable positive predictive value (PPV) and negative predictive value (NPV) of $95 \%$, suggesting that these three circRNAs can predict HBVassociated HCC patients or healthy individuals (116).

In addition to the typical miRNA sponging mechanism, post-transcriptional modification of circRNAs may influence translation. The phenomenon was confirmed by overexpressed circ_KIAA1429 in HCC (120). Some circRNAs are associated with drug resistance in $\mathrm{HCC}$ treatment. For PD-1 antibodymediated immunotherapy, circMET makes HCC cells resistant to $\mathrm{PD}-1$ by enhancing the therapeutic microenvironment of immunosuppressive tumors (130). The mechanism revealed that circMET as a sponge of miR-30-5p could promote SNAILmediated dipeptidyl 4 (DPP4) expression, leading to CXCL10 degradation, and CXCL10 is a key chemokine in driving intratumor infiltration of effector $\mathrm{T}$ cells and may cause subsequent resistance to anti-PD-1 therapy.

Currently, exosomal circRNAs play significant roles in HCC progression, and several exosomal circRNAs function as either diagnostic/prognostic biomarkers or oncogenic/tumorsuppressive factors in $\operatorname{HCC}(65,131)$. The first study in 2015 demonstrated the presence of abundant circRNA inexosomes (132). Previous studies have shown that three exosomes secreted by HCC cells with high metastatic potential, the circPTGR1 subtype, can enhance HCC metastasis with low metastatic potential via the miR449a-Met signaling pathway (133). The exosomal circ-0051443 is produced from normal cells and transferred into HCC cells to inhibit the progression of HCC through competitive combination with miR-331-3p and aggravating apoptosis and cell cycle arrest of HCC cells (134). Therefore, recently described properties of circRNAs can not only help us improve understanding but also contribute to the clinical diagnosis and treatment of HCC.

\section{PROTEOMICS CHARACTERISTICS}

Proteomics are a large-scale study to unveil the profile of proteins expressed under certain biological conditions (135). Recently, proteomics has been used to analyze the overall level of proteins to investigate the pathogenesis, cellular patterns, and functional practices of $\mathrm{HBV}$-associated HCC. With alterations in protein expression in the progression of HCC, some proteins can be considered as potential biomarkers for diagnosis and therapy (136). In a validation study, 28 proteins could separate acute-on-chronic liver failure (ACLF) from CHB patients, the proteomic features developed in this study reflected deficiencies of important hematologic functions in patients with HBVACLF, and demonstrated the potential for diagnosis and risk prediction of HBV-ACLF, complementing current clinical-based parameters (137). Compared with serum sample, urine sample is non-invasive and easy to collect, making it more suitable for HCC surveillance in high-risk patients who require frequent examination. Seven protein features were selected in a previous study; among them, HPX, APOH, APCS and PLG were upregulated in HCC urine samples, and GOT1, GLRX, and NCR3LG1 were downregulated (138).

Presently, mass spectrometry is considered a means of protein identification. Pollination mass spectrometry has developed rapidly with the emergence of electrospray ionization mass spectrometry (ESI) and matrix-assisted laser desorption and ionization time of flight mass spectrometry (MALDI-TOFMS), which provide technical support for proteomics research. Because of its high throughput and sensitivity, MALDI-TOFMS has provided an optimal response surface for proteomics research as an advanced technique in recent years. The application of MALDI-TOF-MS by the translocation of boron effectively detects the differential serum proteins of $\mathrm{HBV}$ associated HCC, providing important support for diagnosis and treatment of HBV-associated HCC. Tandem mass tag (TMT), isobaric tags for relative and absolute quantification (iTRAQ), stable isotope labeling by amino acids in cell culture (SILAC), and liquid mass spectrometry are used to identify differential proteins. Among them, iTRAQ is considered as one of the most robust quantitative proteomics techniques (139). Compared with 2D gel electrophoresis, iTRAQ technology has many advantages including recognition of low-abundance proteins and high-throughput capabilities. Based on iTRAQ quantitative comparative proteomics, researchers have utilized liquid chromatograph-mass spectrometer/mass spectrometer (LC-MS/MS) to recognize and quantitate differential proteins in HepG2 cell lines stably containing different functional domains of $\mathrm{HBx}$, and p90 ribosomal S6 kinase 2 (RSK2) has been identified as a new host protein that plays a key role in $\mathrm{HBx}$ enhancing HBV replication (140). Plasma fibronectin was demonstrated to be related with serum clearance of HBsAg and may be a potential predictor of "functional cure" of CHB by iTRAQ-based quantitative proteomics (141), meanwhile the TMT isobaric labeling-based technology was used to quantitatively characterize the renal proteome of HBV transgenic mice, and to elucidate the pathogenesis of $\mathrm{HBV}$-associated glomerulonephritis (HBVGN) (142). Additionally, proteomic analyses of formalin-fixed paraffin-embedded (FFPE) HCC graft samples, conducted using a label-free proteome mass spectrometry workflow, were used to characterize the global quantitative analysis of protein expression profiles after gene therapy and to identify differentially expressed proteins (143). Thus, a proteomic strategy to identify HCC 
candidate biomarkers requires more integrated analysis, and no single methodology can perform this function.

At the same time, the application of proteomics also plays a role revealing the mechanism of the regulation of $\mathrm{HBV}$ viral protein in HCC progression, such as HBx, HBs, and HBc. High expressions of GNA13 and GNAi3, belong to the members of the guanine nucleotide-binding protein subunit $\alpha$ (GNA) protein family, are involved in the development of liver cancer through positive and negative regulatory mechanisms, respectively (144, 145). Additionally, recent studies found that the HBx protein promotes the expression of the DNA methylation enzymes DNMT1 and DNMT3A, thereby increasing the methylation level of CpG islands in the promoter region of GNA14 and inhibiting GNA14 expression (146). Endoplasmic reticulum (ER) dysfunction is closely associated with malignant transformation, particularly liver transformation (147). Reticulon (RTN), which is located in the ER, is important for ER maintenance (148). Relevant research results show that HBsAg promotes HCC development by inducing non-mutagenic inactivation of the p53 signaling pathway through the interacting protein RTN3, and proteomic analysis of $\mathrm{HBV}$ core protein $(\mathrm{HBc})$ interactions in the nucleus of HepaRG cells revealed that the interaction of $\mathrm{HBc}$ with multiple RNA-binding proteins (RBPs) that regulate viral mRNA metabolism provides a new perspective to develop novel host-targeted antiviral strategies (149). Ribosome profiling (RiboSeq) is a novel technology, which could accurately locate the position of ribosomes on mRNA. By combining with RNAribosome profiling and proteomics, novel post-translational events hereby detected were then characterize. One study integrated multi-omics analysis, such as RNA-seq, Ribosome profiling and quantitative mass spectrometry, uncovered that an RNA element derived from HBV enhancer I forms a stemloop which suppresses HBV translation (150). Furthermore, 11 RBPs (RAN, BRIX1, SMG5, DYNC1H1, PRKDC, GTPBP4, and so on) are associated with the overall survival of HCC patients by integrating RNA sequencing and proteomic data (13). These RBPs bind to various RNAs, such as mRNAs, rRNAs, ncRNAs, play a critical role in post-transcriptional gene regulation (PTGR) and are associated with RNA splicing, transport, maturation, degradation, stability, and translation (151). Therefore, they may be drug targets that will help optimize future clinical therapies.

The role of post-translational modifications (PTMs) includes modification events of biochemical functional groups, such as phosphorylation, glycosylation, ubiquitination and so on, which also play an key role on regulating development of HCC. Studies have proved that PTMs are very rich, and the same protein may be modified at multiple sites, which contributes to the diversity of protein structure and function (152). Recent studies have shown that HBV proteins can be modified by different types of PTMs, which affect their protein-protein interaction, subcellular localization and function (153). Recently, multiomics platforms have performed to systematically interrogate HBV-host interactions. At the transcriptome, proteome and phosphoproteome levels of liver cancer tissues, it was observed that the key enzymes of glycolysis pathway (HK2, ALDOA, PKM2) were significantly up-regulated, indicating that liver cancer has an increased demand for glucose metabolism, and phosphorylation of glycolytic enzymes including ALDOA, may drive metabolic reprogramming and proliferation in liver cancer with CTNNB1 mutation (14). A proteomic analysis had identified that SRSF10as a RNA-binding proteins (RBPs) could be able to alter its phosphorylation and then to regulate HBV RNA metabolism (154). Using high-resolution mass spectrometry, 22,539 phosphorylation sites on 5431 proteins had identified in an HBx-transgenic mouse model of HCC, and these phosphoproteome data highlight potential mechanisms of kinase regulation, especially kinase activities of Src family kinases (SFKs), PKCs, MAPKs, and ROCK2 in HCC (155). Hu et al. revealed the relationship between metabolic reprogramming and antiviral innate immunity against HBV infection usingLC-MS/MS. And O-linked$\mathrm{N}$-acetylglucosaminylation (O-GlcNAcylation) was proved to regulate host antiviral response against $\mathrm{HBV}$, and $\mathrm{O}-$ GlcNAcylation of SAMHD1, as an effector of innate immunity, could stabilize samhd1 structure and enhance host antiviral activity (156). Protein glycosylation is a well-known posttranslational modifications and analysis of which based on MS technology commonly. It was reported that the change of glycan heterogeneity in HCC promotes the occurrence, progression and metastasis of tumor, and $\mathrm{N}$-glycosylation is related to the development and progression of HBV-related HCC $(157,158)$. They showed that altered N-glycopeptide may be part of the unique glycan characteristics, indicating the IgA mediated mechanism and providing potential diagnostic clues for HBV-related HCC. Interferon- $\alpha$ (IFN- $\alpha$ ) signaling is crucial for antiviral response. Through high-throughput RNAi screening, Chen et al. identified that the methylation of STAT1 catalyzed by methyltransferase SETD2 was determined to be IFN $\alpha$-dependent antiviral immunity and showed the potential of SETD2 in controlling HBV infection (159). In the process of viral infection, ubiquitin system is an important part of cellular defense mechanism. Recent studies have shown that ubiquitination may be involved in the degradation of host protein after HBV integration, and there is a negative correlation between the whole proteome and ubiquitin group by performing an Ubiscan quantifcation analysis based on stable isotope labeling of amino acids in cell culture (SILAC) of HepG2.2.15 and HepG2 cell lines (145). Overall, HBV infection mediated changes in post-translational modifications will provide valuable data for further study of the pathogenesis of HBV-related HCC.

\section{METABOLOMICS CHARACTERISTICS}

The liver is an internal organ in the human body and is responsible for substrate metabolic and detoxification activities. As a hepatotropic virus, the infectious status of HBV affects liver metabolic function. Understanding how HBV infection relates to hepatic metabolism may provide new insights into the pathogenesis of HBV infection.

Metabolomics is the study of the profile of metabolites (e.g., amino acids, lipids, sugars, and hormones) that are detectable under certain conditions. Tumors from HCC patients may alter metabolic pathways, and the resulting changes in 
nutritional supply are essential to overcome nutritional hunger and changes in environmental conditions (160). Compared with other "omics," metabolomics not only provides the most direct snapshot of the actual functional and physiological state of biological networks but also establishes a key technique to investigate metabolic alterations in carcinogenesis $(161,162)$. Currently, no standard or routine screening test exists for liver cancer. X-ray computed tomography scan, ultrasound and $\alpha$ fetoprotein (AFP) are the typical tests used to screen for liver cancer, while liver biopsy is used as the gold standard (163). Metabolomics studies uncover new insights into the biological understanding of HCC and reveal particular implications related to clinical and therapeutic plans. The main techniques applied to metabolomics are nuclear magnetic resonance spectroscopy (NMR), gas chromatography-mass spectrometry (GC-MS) and LC-MS (164). Recent studies based on mass spectrometry and next-generation sequencing unveiled the active status of signaling pathways and reprogramming of hepatic metabolism in HBV-associated HCC at the genomic and proteomic levels $(14,38)$. MS-based technologies can provide measures of the global changes in protein abundance related to the deregulation of signaling and metabolic pathways in HCC. NMR spectroscopy-based metabolomics provide a non-targeted, quantitative snapshot of global metabolite abundance to provide additional biological insights that cannot be deciphered by proteomics alone (165). Additionally, the combination of GCMS- and NMR-based metabolomic platforms is promising because the application of multi-metabolomics platforms yields a superior biomarker panel to diagnose bipolar disorder (166). Previously, in the field of metabonomics, substantial efforts have been made to search for biomarkers of HCC, some of which are candidate biomarkers (167). However, how the metabolic phenotype is driven remains unclear in HBV-associated HCC.

The metabolomics profile identified in HCC offers unprecedented opportunities to screen candidate metabolites for early diagnosis and treatment. From the perspective of metabolomics, lipid, energy and amino acid metabolism may be affected in the progress of HCC (168). Glycolysis-related metabolites, TCA cycles and pyrimidine synthesis change in tumor tissues at different stages. Carbohydrates that are energy sources of hepatocytes and carbohydrates, such as mannose, galactose, and arabinose, are significantly reduced in the serum of HCC patients and other liver diseases (169). The reductional feature of carbohydrates in HCC is also consistent with most cancer cells, in which they can produce energy by undergoing high speed glycolysis followed by lactic acid fermentation in the cytoplasm instead of using oxidative phosphorylation in mitochondria (170). Dysregulation of amino acid metabolism is associated with liver disease and HCC development (171). Because of increased tumor protein synthesis and energy demand of amino acids in malignant tumor cells (172), multiple amino acids, such as proline, lysine, ornithine, phenylalanine serine, and tyrosine, are upregulated significantly in HCC and HBV-cirrhosis patients (165). Additionally, because of aggressive cell proliferation in HCC, the energy supply and cell membrane synthesis must increase fatty acids including arachidonic acid, which is at a higher level in HBV-cirrhosis and
HCC patients $(173,174)$. Thus, the fatty acids may be involved in the pathogenesis of HCC.

During the viral life cycle, HBV is associated with hepatic metabolism. This evidence of the involvement of cell metabolism in HBV-associated cancer prognosis raises interest in metabolic enzymes-targeted cancer therapy (175). In the study of the metabolic pathway, omics evidence also shows that immune patterns between HBV and the host are closely associated with the disease progression of patients infected with viruses, and metabolic alterations can be regulated by HBV protein in HCC cells. Through multiomic analysis, Xie et al. demonstrated that $\mathrm{HBV}$ core protein $(\mathrm{HBc})$ increased the secretion of metabolites and expression of metabolic enzymes in HCC cells, and activated the amino acid and glycolysis metabolism pathways (176). Similar to previous studies, $\mathrm{HBc}$ can bind to human gene promoters to mediate primary metabolic processes (177). The metabolic components of liver microenvironment are actively involved in the occurrence and development of HBV infection, and hot-spot mutations in $\mathrm{HBc}$, including L60V, I97L, and S87G, affect viral replication, persistence and immune pathogenesis in $\mathrm{CHB}$ infection $(178,179)$. Additionally, HBs, HBx, and $\mathrm{HBc}$ integrate into human genes to affect patient survival (47). Cellular retinoid X receptor alpha (RXR $\alpha)$, a key transcription factor for monitoring hepatic lipid metabolism, regulates $\mathrm{HBV}$ infection, and the arachidonic acid (AA)/eicosanoid biosynthesis pathway may be involved in the regulation of HBV infection (180). Therefore, hepatic lipid homeostasis is critical to modulate viral infection.

\section{MICROBIOME CHARACTERISTICS}

Microbiome is becoming a potentially key regulator of cancer development, especially in gut and liver microbiomes. Because the microbial group is mainly located in the intestines, the gut microbiome is the most studied and associated with a variety of human diseases, including Alzheimer's disease, cardiovascular disease, diabetes, arthritis and cancer, which is not surprising (181). Actually, gut bacteria play a key role in maintaining gutliver axis health, and intestinal flora disorders occurred in 20$75 \%$ of patients with chronic liver disease (182). One study carried out $16 \mathrm{~S}$ rRNA analyses in 35 individuals with HBV related HCC (B-HCC). Compared with 22 individuals with non$\mathrm{HBV} /$ non-HCV (NBNC) related HCC (NBNC-HCC), the species richness of fecal microbiota of B-HCC patients was much higher. The results showed that there are differences in the number of bacteria involved in different functions or biological pathways (183). Zheng et al. also showed that gut microbiota disorder was more common in patients with liver cirrhosis-induced HCC, however, hepatitis virus infection was not associated with intestinal microbial imbalance. The data indicated that butyrate-producing genera was decreased and genera producinglipopolysaccharide (LPS) was increased in liver cirrhosis-induced HCC (184). In HBV induced tumors, this tumor inhibitory effect is inferred based on the down-regulation of microorganisms that induce cancer and stem cell pathway. Using next-generation RNA-sequencing against HBV-related HCC patients and adjacent 
normal liver tissues, the results of this study suggest that both heavy drinking and HBV infection may use the tumor microbiome to promote the development of cancer, however, only $\mathrm{HBV}$ infection could downregulate microorganisms that may promote stem cell function (185). They suggested strains of Escherichia coli were to be potentially important to HCC progression. The change of liver microenvironment in HCC patients may lead to the change of bacterial level in gut. Overall, gut-liver-axis could be used to monitor and prevent the progress of liver disease and liver cancer.

\section{CONCLUSIONS}

The initiation and progression of liver cancer are involved in multisystem and multilevel pathological changes. Single-omics analysis plays a key role in the diagnosis and therapy of diseases in modern society. However, with the development of research technologies and needs, single-omics is not sufficiently comprehensive; one type of omics change can't represent the overall status of the disease, only $10-20 \%$ of transcriptome changes are associated with proteomic data (186). Abnormal gene expression is also a risk factor leading to tumor cell formation. Changes in DNA nucleotide sequences and epigenetic mechanisms may result in aberrant gene expression profiles. The entire regulatory network may be clearly illustrated by more advanced and sensitive high-throughput omics technologies. Single-omics research is crucial, and this method often has some limitations. By contrast, the integrated analysis of multi-omics data can better describe the overall changes in liver cancer, thus achieving more valuable data in the diagnosis and development of therapeutic targets in human diseases. The latest advances in analytical technology, including ultra deep sequencing, have made multi-omicsmulti-omics analysis faster, more accurate and simpler. Many omics technologies are widely used in cancer research. The introduction of omics technology to analyze the

\section{REFERENCES}

1. Sung H, Ferlay J, Siegel RL, Laversanne M, Soerjomataram I, Jemal A, et al. Global cancer statistics 2020: GLOBOCAN estimates of incidence and mortality worldwide for 36 cancers in 185 countries. CA Cancer J Clin. (2021) 71:209-49. doi: 10.3322/caac.21660

2. Llovet JM, Zucman-Rossi J, Pikarsky E, Sangro B, Schwartz M, Sherman M, et al. Hepatocellular carcinoma. Nat Rev Dis Primers. (2016) 2:16018. doi: $10.1038 /$ nrdp. 2016.18

3. Zucman-Rossi J, Villanueva A, Nault JC, Llovet JM. Genetic landscape and biomarkers of hepatocellular carcinoma. Gastroenterology. (2015) 149:122639.e4. doi: 10.1053/j.gastro.2015.05.061

4. Revill PA, Chisari FV, Block JM, Dandri M, Gehring AJ, Guo $\mathrm{H}$, et al. A global scientific strategy to cure hepatitis B. Lancet Gastroenterol Hepatol. (2019) 4:545-58. doi: 10.1016/S2468-1253(19)3 0119-0

5. Terrault NA, Bzowej NH, Chang KM, Hwang JP, Jonas MM, Murad MH, et al. AASLD guidelines for treatment of chronic hepatitis B. Hepatology. (2016) 63:261-83. doi: 10.1002/hep. 28156

6. Hung TH, Liang CM, Hsu CN, Tai WC, Tsai KL, Ku MK, et al. Association between complicated liver cirrhosis and the risk of hepatocellular carcinoma in Taiwan. PLoS ONE. (2017) 12:e0181858. doi: 10.1371/journal.pone.0181858 pathogenesis or treatment of HBV-associated HCC may help not only to identify biomarkers for clinical use but also to explore the experimental research background of the pathogenesis of various diseases. Several studies have detected exome sequencing or whole genome sequencing and have used genome sequencing to identify driver gene mutations in liver cancer. The application of currently rapidly developing omics technology will promote the development of knowledge-based diagnosis and treatment strategies. In the future, more cohort studies will explore the prognostic factors of HCC patients, and candidate genes related to prognosis or recurrence of HCC will be identified using omics technology.

\section{AUTHOR CONTRIBUTIONS}

YW, DC, and JX conceived the topic. YW and DC conducted literature review, drafted the manuscript, designed the figures, and tables. JX, WL, JW, and DJ polished the manuscript. All authors approved the submitted version.

\section{FUNDING}

This work was supported by the Zhejiang Provincial Natural Science Foundation of China (No. LBY21H190001), National Natural Science Foundation of China (Nos. 81871709, 91846103, and 81971994), and Zhejiang Provincial Key Research and Development Program (No. 2020C03032).

\section{ACKNOWLEDGMENTS}

We gratefully appreciate the editors with native English speaking at American Journal Experts (AJE) for providing highly qualified English language editing service (Verification Code: 1F38-D0F587DC-ABEB-1AA3) for our article.
7. Xiao LL, Wu XX, Chen JJ, Yan D, Shi DY, Huang JR, et al. Progress in hepatitis B virus-related acute-on-chronic liver failure treatment in China: a large, multicenter, retrospective cohort study using a propensity score matching analysis. Hepatobiliary Pancreat Dis Int. (2021) S14993872(21)00119-3. doi: 10.1016/j.hbpd.2021.05.010

8. Tang LSY, Covert E, Wilson E, Kottilil S. Chronic Hepatitis B Infection: A Review. JAMA. (2018) 319:1802-13. doi: 10.1001/jama.2018.3795

9. Chen JD, Yang HI, Iloeje UH, You SL, Lu SN, Wang LY, et al. Carriers of inactive hepatitis B virus are still at risk for hepatocellular carcinoma and liver-related death. Gastroenterology. (2010) 138:174754. doi: 10.1053/j.gastro.2010.01.042

10. Nassal M. HBV cccDNA: viral persistence reservoir and key obstacle for a cure of chronic hepatitis B. Gut. (2015) 64:1972-84. doi: 10.1136/gutjnl-2015-309809

11. Wang $\mathrm{Y}, \mathrm{Wu} \mathrm{J}, \mathrm{Xu}$ J, Lin S. Clinical significance of high expression of stanniocalcin-2 in hepatocellular carcinoma. Biosci Rep. (2019) 39:BSR20182057. doi: 10.1042/BSR20182057

12. Muller M, Bird TG, Nault JC. The landscape of gene mutations in cirrhosis and hepatocellular carcinoma. J Hepatol. (2020) 72:9901002. doi: 10.1016/j.jhep.2020.01.019

13. Wang L, Zhang Z, Li Y, Wan Y, Xing B. Integrated bioinformatic analysis of RNA binding proteins in hepatocellular carcinoma. Aging (Albany NY). (2020) 13:2480-505. doi: 10.18632/aging.202281 
14. Gao Q, Zhu H, Dong L, Shi W, Chen R, Song Z, et al. Integrated proteogenomic characterization of HBV-related hepatocellular carcinoma. Cell. (2019) 179:561-77.e22. doi: 10.1016/j.cell.2019.08.052

15. Kumar R, Sharma A, Iqbal MS, Srivastava JK. Therapeutic promises of chlorogenic acid with special emphasis on its anti-obesity property. Curr Mol Pharmacol. (2020) 13:7-16. doi: 10.2174/1874467212666190716145210

16. Muthuramalingam P, Jeyasri R, Valliammai A, Selvaraj A, Karthika C, Gowrishankar S, et al. Global multi-omics and systems pharmacological strategy unravel the multi-targeted therapeutic potential of natural bioactive molecules against COVID-19: an in silico approach. Genomics. (2020) 112:4486-504. doi: 10.1016/j.ygeno.2020.08.003

17. Yoon SJ, Kim JY, Long NP, Min JE, Kim HM, Yoon JH, et al. Comprehensive multi-omics analysis reveals aberrant metabolism of epstein-barr-virusassociated gastric carcinoma. Cells. (2019) 8:1220. doi: 10.3390/cells81 01220

18. Su Y, Chen D, Yuan D, Lausted C, Choi J, Dai CL, et al. Multi-omics resolves a sharp disease-state shift between mild and moderate COVID-19. Cell. (2020) 183:1479-95.e20. doi: 10.1016/j.cell.2020.10.037

19. Whisnant AW, Jurges CS, Hennig T, Wyler E, Prusty B, Rutkowski AJ, et al. Integrative functional genomics decodes herpes simplex virus 1. Nat Commun. (2020) 11:2038. doi: 10.1038/s41467-020-15992-5

20. Murphy CM, Xu Y, Li F, Nio K, Reszka-Blanco N, Li X, et al. Hepatitis B virus $\mathrm{X}$ protein promotes degradation of SMC5/6 to enhance HBV replication. Cell Rep. (2016) 16:2846-54. doi: 10.1016/j.celrep.2016.08.026

21. Jiang Y, Han Q, Zhao H, Zhang J. The mechanisms of HBVinduced hepatocellular carcinoma. J Hepatocell Carcinoma. (2021) 8:435-50. doi: 10.2147/JHC.S307962

22. Flavahan WA, Gaskell E, Bernstein BE. Epigenetic plasticity and the hallmarks of cancer. Science (New York, NY). (2017) 357:eaal2380. doi: 10.1126/science.aal2380

23. Zhang HT, Chen GG, Hu BG, Zhang ZY, Yun JP, He ML, et al. Hepatitis $B$ virus $x$ protein induces autophagy via activating death-associated protein kinase. J Viral Hepat. (2014) 21:642-9. doi: 10.1111/jvh.12191

24. Meoni G, Lorini S, Monti M, Madia F, Corti G, Luchinat C, et al. The metabolic fingerprints of $\mathrm{HCV}$ and $\mathrm{HBV}$ infections studied by nuclear magnetic resonance spectroscopy. Sci Rep. (2019) 9:4128. doi: 10.1038/s41598-019-40028-4

25. Zheng B, Yang Y, Han Q, Yin C, Pan Z, Zhang J. STAT3 directly regulates NKp46 transcription in NK cells of HBeAg-negative CHB patients. J Leukoc Biol. (2019) 106:987-96. doi: 10.1002/JLB.2A1118-421R

26. Laurent-Puig P, Legoix P, Bluteau O, Belghiti J, Franco D, Binot F, et al. Genetic alterations associated with hepatocellular carcinomas define distinct pathways of hepatocarcinogenesis. Gastroenterology. (2001) 120:176373. doi: 10.1053 /gast.2001.24798

27. Boyault S, Rickman DS, de Reynies A, Balabaud C, Rebouissou S, Jeannot E, et al. Transcriptome classification of HCC is related to gene alterations and to new therapeutic targets. Hepatology. (2007) 45:4252. doi: 10.1002/hep. 21467

28. Huang H, Ren Z, Gao X, Hu X, Zhou Y, Jiang J, et al. Integrated analysis of microbiome and host transcriptome reveals correlations between gut microbiota and clinical outcomes in HBV-related hepatocellular carcinoma. Genome Med. (2020) 12:102. doi: 10.1186/s13073-020-00796-5

29. Yang SL, Liu LP, Sun YF, Yang XR, Fan J, Ren JW, et al. Distinguished prognosis after hepatectomy of HBV-related hepatocellular carcinoma with or without cirrhosis: a long-term follow-up analysis. J Gastroenterol. (2016) 51:722-32. doi: 10.1007/s00535-015-1146-0

30. Asahina Y, Tsuchiya K, Nishimura T, Muraoka M, Suzuki Y, Tamaki $\mathrm{N}$, et al. alpha-fetoprotein levels after interferon therapy and risk of hepatocarcinogenesis in chronic hepatitis C. Hepatology. (2013) 58:125362. doi: 10.1002/hep. 26442

31. Forner A, Llovet JM, Bruix J. Hepatocellular carcinoma. Lancet. (2012) 379:1245-55. doi: 10.1016/S0140-6736(11)61347-0

32. Takeda $H$, Takai $A$, Inuzuka $T$, Marusawa $H$. Genetic basis of hepatitis virus-associated hepatocellular carcinoma: linkage between infection, inflammation, and tumorigenesis. J Gastroenterol. (2017) 52:26-38. doi: 10.1007/s00535-016-1273-2

33. You JS, Jones PA. Cancer genetics and epigenetics: two sides of the same coin? Cancer Cell. (2012) 22:9-20. doi: 10.1016/j.ccr.2012.06.008
34. Baylin SB, Jones PA. A decade of exploring the cancer epigenome biological and translational implications. Nat Rev Cancer. (2011) 11:72634. doi: $10.1038 / \mathrm{nrc} 3130$

35. Chiba $\mathrm{T}$, Marusawa $\mathrm{H}$, Ushijima $\mathrm{T}$. Inflammation-associated cancer development in digestive organs: mechanisms and roles for genetic and epigenetic modulation. Gastroenterology. (2012) 143:550-63. doi: 10.1053/j.gastro.2012.07.009

36. Schulze K, Imbeaud S, Letouze E, Alexandrov LB, Calderaro J, Rebouissou $\mathrm{S}$, et al. Exome sequencing of hepatocellular carcinomas identifies new mutational signatures and potential therapeutic targets. Nat Genet. (2015) 47:505-11. doi: 10.1038/ng.3252

37. Villanueva A, Newell P, Chiang DY, Friedman SL, Llovet JM. Genomics and signaling pathways in hepatocellular carcinoma. Semin Liver Dis. (2007) 27:55-76. doi: 10.1055/s-2006-960171

38. Schulze K, Nault JC, Villanueva A. Genetic profiling of hepatocellular carcinoma using next-generation sequencing. J Hepatol. (2016) 65:103142. doi: 10.1016/j.jhep.2016.05.035

39. Zhang Y, Chen F, Fonseca NA, He Y, Fujita M, Nakagawa H, et al. High-coverage whole-genome analysis of 1220 cancers reveals hundreds of genes deregulated by rearrangement-mediated cis-regulatory alterations. Nat Commun. (2020) 11:736. doi: 10.1038/s41467-01913885-w

40. Fujimoto A, Furuta M, Totoki Y, Tsunoda T, Kato M, Shiraishi Y, et al. Whole-genome mutational landscape and characterization of noncoding and structural mutations in liver cancer. Nat Genet. (2016) 48:5009. doi: $10.1038 / \mathrm{ng} .3547$

41. Shiraishi Y, Fujimoto A, Furuta M, Tanaka H, Chiba K, Boroevich $\mathrm{KA}$, et al. Integrated analysis of whole genome and transcriptome sequencing reveals diverse transcriptomic aberrations driven by somatic genomic changes in liver cancers. PLoS ONE. (2014) 9:e114263. doi: 10.1371/journal.pone.0114263

42. Bruix J, Boix L, Sala M, Llovet JM. Focus on hepatocellular carcinoma. Cancer Cell. (2004) 5:215-9. doi: 10.1016/S1535-6108(04)00058-3

43. Toh ST, Jin Y, Liu L, Wang J, Babrzadeh F, Gharizadeh B, et al. Deep sequencing of the hepatitis B virus in hepatocellular carcinoma patients reveals enriched integration events, structural alterations and sequence variations. Carcinogenesis. (2013) 34:787-98. doi: 10.1093/carcin/bgs406

44. Hanahan D, Weinberg RA. Hallmarks of cancer: the next generation. Cell. (2011) 144:646-74. doi: 10.1016/j.cell.2011.02.013

45. Jin Y, Lee WY, Toh ST, Tennakoon C, Toh HC, Chow PK, et al. Comprehensive analysis of transcriptome profiles in hepatocellular carcinoma. J Transl Med. (2019) 17:273. doi: 10.1186/s12967-019-2025-X

46. Dong H, Zhang L, Qian Z, Zhu X, Zhu G, Chen Y, et al. Identification of HBV-MLL4 integration and its molecular basis in Chinese hepatocellular carcinoma. PLoS ONE. (2015) 10:e0123175. doi: 10.1371/journal.pone.0123175

47. Sung WK, Zheng H, Li S, Chen R, Liu X, Li Y, et al. Genome-wide survey of recurrent HBV integration in hepatocellular carcinoma. Nat Genet. (2012) 44:765-9. doi: 10.1038/ng.2295

48. Huang W, Skanderup AJ, Lee CG. Advances in genomic hepatocellular carcinoma research. Gigascience. (2018) 7:giy135. doi: 10.1093/gigascience/giy135

49. Jhunjhunwala S, Jiang Z, Stawiski EW, Gnad F, Liu J, Mayba O, et al. Diverse modes of genomic alteration in hepatocellular carcinoma. Genome Biol. (2014) 15:436. doi: 10.1186/PREACCEPT-1790146428112469

50. Hama N, Totoki Y, Miura F, Tatsuno K, Saito-Adachi M, Nakamura H, et al. Epigenetic landscape influences the liver cancer genome architecture. Nat Commun. (2018) 9:1643. doi: 10.1038/s41467-018-03999-y

51. Llovet JM, Montal R, Sia D, Finn RS. Molecular therapies and precision medicine for hepatocellular carcinoma. Nat Rev Clin Oncol. (2018) 15:599616. doi: 10.1038/s41571-018-0073-4

52. Zhao LH, Liu X, Yan HX, Li WY, Zeng X, Yang Y, et al. Genomic and oncogenic preference of HBV integration in hepatocellular carcinoma. Nat Commun. (2016) 7:12992. doi: 10.1038/ncomms13591

53. Jiang Z, Jhunjhunwala S, Liu J, Haverty PM, Kennemer MI, Guan Y, et al. The effects of hepatitis B virus integration into the genomes of hepatocellular carcinoma patients. Genome Res. (2012) 22:593-601. doi: 10.1101/gr.133926.111 
54. Knipe DM, Lieberman PM, Jung JU, McBride AA, Morris KV, Ott M, et al. Snapshots: chromatin control of viral infection. Virology. (2013) 435:14156. doi: 10.1016/j.virol.2012.09.023

55. Lilley CE, Chaurushiya MS, Weitzman MD. Chromatin at the intersection of viral infection and DNA damage. Biochim Biophys Acta. (2010) 1799:31927. doi: 10.1016/j.bbagrm.2009.06.007

56. Lubecka K, Flower K, Beetch M, Qiu J, Kurzava L, Buvala H, et al. Locispecific differences in blood DNA methylation in HBV-negative populations at risk for hepatocellular carcinoma development. Epigenetics. (2018) 13:605-26. doi: 10.1080/15592294.2018.1481706

57. Villanueva A, Llovet JM. Liver cancer in 2013: mutational landscape of HCC-the end of the beginning. Nat Rev Clin Oncol. (2014) 11:734. doi: 10.1038/nrclinonc.2013.243

58. Cancer Genome Atlas Research Network. Electronic address wbe, Cancer Genome Atlas Research N. Comprehensive and integrative genomic characterization of hepatocellular carcinoma. Cell. (2017) 169:132741.e23. doi: 10.1016/j.cell.2017.05.046

59. Lou J, Zhang L, Lv S, Zhang C, Jiang S. Biomarkers for hepatocellular carcinoma. Biomark Cancer. (2017) 9:1-9. doi: 10.1177/1179299X16 684640

60. Lambert MP, Paliwal A, Vaissiere T, Chemin I, Zoulim F, Tommasino M, et al. Aberrant DNA methylation distinguishes hepatocellular carcinoma associated with HBV and HCV infection and alcohol intake. J Hepatol. (2011) 54:705-15. doi: 10.1016/j.jhep.2010.07.027

61. Jain S, Chen S, Chang KC, Lin YJ, Hu CT, Boldbaatar B, et al. Impact of the location of CpG methylation within the GSTP1 gene on its specificity as a DNA marker for hepatocellular carcinoma. PLOS ONE. (2012) 7:e35789. doi: 10.1371/journal.pone.0035789

62. Jain S, Chang TT, Hamilton JP, Lin SY, Lin YJ, Evans AA, et al. Methylation of the $\mathrm{CPG}$ sites only on the sense strand of the APC gene is specific for hepatocellular carcinoma. PLoS ONE. (2011) 6:e26799. doi: 10.1371/journal.pone.0026799

63. Moribe T, Iizuka N, Miura T, Kimura N, Tamatsukuri S, Ishitsuka H, et al. Methylation of multiple genes as molecular markers for diagnosis of a small, well-differentiated hepatocellular carcinoma. Int J Cancer. (2009) 125:388-97. doi: 10.1002/ijc.24394

64. Chang H, Yi B, Li L, Zhang HY, Sun F, Dong SQ, et al. Methylation of tumor associated genes in tissue and plasma samples from liver disease patients. Exp Mol Pathol. (2008) 85:96-100. doi: 10.1016/j.yexmp.2008. 07.001

65. Li LM, Liu ZX, Cheng QY. Exosome plays an important role in the development of hepatocellular carcinoma. Pathol Res Pract. (2019) 215:152468. doi: 10.1016/j.prp.2019.152468

66. Shen J, Wang S, Zhang YJ, Kappil M, Wu HC, Kibriya MG, et al. Genomewide DNA methylation profiles in hepatocellular carcinoma. Hepatology. (2012) 55:1799-808. doi: 10.1002/hep.25569

67. Song MA, Kwee SA, Tiirikainen M, Hernandez BY, Okimoto G, Tsai $\mathrm{NC}$, et al. Comparison of genome-scale DNA methylation profiles in hepatocellular carcinoma by viral status. Epigenetics. (2016) 11:46474. doi: 10.1080/15592294.2016.1151586

68. Calvisi DF, Ladu S, Gorden A, Farina M, Lee JS, Conner EA, et al. Mechanistic and prognostic significance of aberrant methylation in the molecular pathogenesis of human hepatocellular carcinoma. J Clin Invest. (2007) 117:2713-22. doi: 10.1172/JCI31457

69. Stefanska B, Cheishvili D, Suderman M, Arakelian A, Huang J, Hallett M, et al. Genome-wide study of hypomethylated and induced genes in patients with liver cancer unravels novel anticancer targets. Clin Cancer Res. (2014) 20:3118-32. doi: 10.1158/1078-0432.CCR-13-0283

70. Xiong L, Wu F, Wu Q, Xu L, Cheung OK, Kang W, et al. Aberrant enhancer hypomethylation contributes to hepatic carcinogenesis through global transcriptional reprogramming. Nat Commun. (2019) 10:335. doi: 10.1038/s41467-018-08245-z

71. Mah WC, Lee CG. DNA methylation: potential biomarker in hepatocellular carcinoma. Biomark Res. (2014) 2:5. doi: 10.1186/2050-7771-2-5

72. Kao WY, Yang SH, Liu WJ, Yeh MY, Lin CL, Liu CJ, et al. Genome-wide identification of blood DNA methylation patterns associated with early-onset hepatocellular carcinoma development in hepatitis B carriers. Mol Carcinog. (2017) 56:425-35. doi: 10.1002/mc.22505
73. Liu Z, Yan H, Zhang J. Blood DNA methylation markers in potentially identified Chinese patients with hepatocellular carcinoma. Pak J Pharm Sci. (2016) 29(Suppl. 4):1451-6.

74. Jain S, Chang TT, Chen S, Boldbaatar B, Clemens A, Lin SY, et al. Comprehensive DNA methylation analysis of hepatitis B virus genome in infected liver tissues. Sci Rep. (2015) 5:10478. doi: 10.1038/srep10478

75. Zhang C, Huang C, Sui X, Zhong X, Yang W, Hu X, et al. Association between gene methylation and HBV infection in hepatocellular carcinoma: a meta-analysis. J Cancer. (2019) 10:6457-65. doi: 10.7150/jca.33005

76. Vivekanandan P, Daniel HD, Kannangai R, Martinez-Murillo F, Torbenson M. Hepatitis B virus replication induces methylation of both host and viral DNA. J Virol. (2010) 84:4321-9. doi: 10.1128/JVI.02280-09

77. Xu RH, Wei W, Krawczyk M, Wang W, Luo H, Flagg $K$, et al. Circulating tumour DNA methylation markers for diagnosis and prognosis of hepatocellular carcinoma. Nat Mater. (2017) 16:115561. doi: 10.1038/nmat4997

78. Pezzuto F, Buonaguro L, Buonaguro FM, Tornesello ML. The role of circulating free DNA and microRNA in non-invasive diagnosis of HBV- and HCV-related hepatocellular carcinoma. Int J Mol Sci. (2018) 19:1007. doi: 10.3390/ijms19041007

79. Chen M, Wei L, Law CT, Tsang FH, Shen J, Cheng CL, et al. RNA N6-methyladenosine methyltransferase-like 3 promotes liver cancer progression through YTHDF2-dependent posttranscriptional silencing of SOCS2. Hepatology. (2018) 67:2254-70. doi: 10.1002/hep.29683

80. Ma JZ, Yang F, Zhou CC, Liu F, Yuan JH, Wang F, et al. METTL14 suppresses the metastatic potential of hepatocellular carcinoma by modulating N(6) -methyladenosine-dependent primary MicroRNA processing. Hepatology. (2017) 65:529-43. doi: 10.1002/hep.28885

81. Helm M, Motorin Y. Detecting RNA modifications in the epitranscriptome: predict and validate. Nat Rev Genet. (2017) 18:275-91. doi: 10.1038/nrg.2016.169

82. Tropberger P, Mercier A, Robinson M, Zhong W, Ganem DE, Holdorf M. Mapping of histone modifications in episomal HBV cccDNA uncovers an unusual chromatin organization amenable to epigenetic manipulation. Proc Natl Acad Sci USA. (2015) 112:E5715-24. doi: 10.1073/pnas.1518090112

83. Yang B, Li B, Jia L, Jiang Y, Wang X, Jiang S, et al. 3D landscape of Hepatitis B virus interactions with human chromatins. Cell Discov. (2020) 6:95. doi: 10.1038/s41421-020-00218-1

84. Alvarez-Astudillo F, Garrido D, Varas-Godoy M, Gutierrez JL, Villanueva RA. Loyola A. The histone variant $\mathrm{H} 33$ regulates the transcription of the hepatitis B virus. Ann Hepatol. (2021) 21:100261. doi: 10.1016/j.aohep.2020.09.005

85. Ding D, Lou X, Hua D, Yu W, Li L, Wang J, et al. Recurrent targeted genes of hepatitis $\mathrm{B}$ virus in the liver cancer genomes identified by a next-generation sequencing-based approach. PLoS Genet. (2012) 8:e1003065. doi: 10.1371/journal.pgen.1003065

86. Lee WY, Bachtiar M, Choo CCS, Lee CG. Comprehensive review of Hepatitis B Virus-associated hepatocellular carcinoma research through text mining and big data analytics. Biol Rev Camb Philos Soc. (2019) 94:35367. doi: $10.1111 /$ brv. 12457

87. Stadelmayer B, Diederichs A, Chapus F, Rivoire M, Neveu G, Alam A, et al. Full-length 5'RACE identifies all major HBV transcripts in HBV-infected hepatocytes and patient serum. J Hepatol. (2020) 73:4051. doi: 10.1016/j.jhep.2020.01.028

88. Chan TH, Lin CH, Qi L, Fei J, Li Y, Yong KJ, et al. A disrupted RNA editing balance mediated by ADARs (Adenosine DeAminases that act on RNA) in human hepatocellular carcinoma. Gut. (2014) 63:83243. doi: 10.1136/gutjnl-2012-304037

89. Meerzaman DM, Yan C, Chen QR, Edmonson MN, Schaefer CF, Clifford RJ, et al. Genome-wide transcriptional sequencing identifies novel mutations in metabolic genes in human hepatocellular carcinoma. Cancer Genomics Proteomics. (2014) 11:1-12.

90. Huang Q, Lin B, Liu H, Ma X, Mo F, Yu W, et al. RNA-Seq analyses generate comprehensive transcriptomic landscape and reveal complex transcript patterns in hepatocellular carcinoma. PLOS ONE. (2011) 6:e26168. doi: 10.1371/journal.pone.0026168

91. Amaddeo G, Cao Q, Ladeiro Y, Imbeaud S, Nault JC, Jaoui D, et al. Integration of tumour and viral genomic characterizations 
in HBV-related hepatocellular carcinomas. Gut. (2015) 64:8209. doi: 10.1136/gutjnl-2013-306228

92. Tang KW, Alaei-Mahabadi B, Samuelsson T, Lindh M, Larsson E. The landscape of viral expression and host gene fusion and adaptation in human cancer. Nat Commun. (2013) 4:2513. doi: 10.1038/ncomms3513

93. Tan AT, Yang N, Lee Krishnamoorthy T, Oei V, Chua A, Zhao X, et al. Use of expression profiles of HBV-DNA integrated into genomes of hepatocellular carcinoma cells to select T cells for immunotherapy. Gastroenterology. (2019) 156:1862-76.e9. doi: 10.1053/j.gastro.2019.01.251

94. Wang YG, Zheng DH, Shi M, Xu XM. T cell dysfunction in chronic hepatitis $B$ infection and liver cancer: evidence from transcriptome analysis. $J$ Med Genet. (2019) 56:22-8. doi: 10.1136/jmedgenet-2018-105570

95. Jiang L, Li X, Cheng Q, Zhang BH. Plasma microRNA might as a potential biomarker for hepatocellular carcinoma and chronic liver disease screening. Tumour Biol. (2015) 36:7167-74. doi: 10.1007/s13277-015-3446-7

96. Thietart S, Rautou PE. Extracellular vesicles as biomarkers in liver diseases: a clinician's point of view. J Hepatol. (2020) 73:1507-25. doi: 10.1016/j.jhep.2020.07.014

97. Yu J, Xu QG, Wang ZG, Yang Y, Zhang L, Ma JZ, et al. Circular RNA cSMARCA5 inhibits growth and metastasis in hepatocellular carcinoma. J Hepatol. (2018) 68:1214-27. doi: 10.1016/j.jhep.2018.01.012

98. Feng J, Yang $G$, Liu $Y$, Gao $Y$, Zhao $M$, Bu $Y$, et al. LncRNA PCNAP1 modulates hepatitis B virus replication and enhances tumor growth of liver cancer. Theranostics. (2019) 9:5227-45. doi: 10.7150/thno. 34273

99. Niu JT, Zhang LJ, Huang YW, Li C, Jiang N, Niu YJ. MiR-154 inhibits the growth of laryngeal squamous cell carcinoma by targeting GALNT7. Biochem Cell Biol. (2018) 96:752-60. doi: 10.1139/bcb-2018-0047

100. Huang JY, Chen HL, Shih C. MicroRNA miR-204 and miR-1236 inhibit hepatitis B virus replication via two different mechanisms. Sci Rep. (2016) 6:34740. doi: 10.1038/srep34740

101. Fornari F, Ferracin M, Trerè D, Milazzo M, Marinelli S, Galassi $\mathrm{M}$, et al. Circulating microRNAs, miR-939, miR-595, miR-519d and miR-494, identify cirrhotic patients with HCC. PLoS ONE. (2015) 10:e0141448. doi: 10.1371/journal.pone.0141448

102. Tian XP, Wang CY, Jin XH, Li M, Wang FW, Huang WJ, et al. Acidic microenvironment up-regulates exosomal miR-21 and miR-10b in earlystage hepatocellular carcinoma to promote cancer cell proliferation and metastasis. Theranostics. (2019) 9:1965-79. doi: 10.7150/thno.30958

103. Gabory A, Jammes H, Dandolo L. The H19 locus: role of an imprinted non-coding RNA in growth and development. Bioessays. (2010) 32:47380. doi: 10.1002/bies.200900170

104. Lai MC, Yang Z, Zhou L, Zhu QQ, Xie HY, Zhang F, et al. Long non-coding RNA MALAT-1 overexpression predicts tumor recurrence of hepatocellular carcinoma after liver transplantation. Med Oncol. (2012) 29:1810-6. doi: 10.1007/s12032-011-0004-Z

105. Ding C, Cheng S, Yang Z, Lv Z, Xiao H, Du C, et al. Long non-coding RNA HOTAIR promotes cell migration and invasion via down-regulation of RNA binding motif protein 38 in hepatocellular carcinoma cells. Int J Mol Sci. (2014) 15:4060-76. doi: 10.3390/ijms15034060

106. Cui M, Xiao Z, Wang Y, Zheng M, Song T, Cai X, et al. Long noncoding RNA HULC modulates abnormal lipid metabolism in hepatoma cells through an miR-9-mediated RXRA signaling pathway. Cancer Res. (2015) 75:84657. doi: 10.1158/0008-5472.CAN-14-1192

107. Yang F, Zhang L, Huo XS, Yuan JH, Xu D, Yuan SX, et al. Long noncoding RNA high expression in hepatocellular carcinoma facilitates tumor growth through enhancer of zeste homolog 2 in humans. Hepatology. (2011) 54:1679-89. doi: 10.1002/hep.24563

108. Du Y, Kong G, You X, Zhang S, Zhang T, Gao Y, et al. Elevation of highly upregulated in liver cancer (HULC) by hepatitis B virus X protein promotes hepatoma cell proliferation via down-regulating p18. J Biol Chem. (2012) 287:26302-11. doi: 10.1074/jbc.M112.342113

109. Kim SS, Baek GO, Son JA, Ahn HR, Yoon MK, Cho HJ, et al. Early detection of hepatocellular carcinoma via liquid biopsy: panel of small extracellular vesicle-derived long noncoding RNAs identified as markers. Mol Oncol. (2021). doi: 10.1002/1878-0261.13049

110. Wu J, Pang R, Li M, Chen B, Huang J, Zhu Y. m6A-Induced LncRNA MEG3 suppresses the proliferation, migration and invasion of hepatocellular carcinoma cell through miR-544b/BTG2 signaling. Onco Targets Ther. (2021) 14:3745-55. doi: 10.2147/OTT.S289198

111. Yang F, Huo XS, Yuan SX, Zhang L, Zhou WP, Wang F, et al. Repression of the long noncoding RNA-LET by histone deacetylase 3 contributes to hypoxia-mediated metastasis. Mol Cell. (2013) 49:108396. doi: 10.1016/j.molcel.2013.01.010

112. Zheng $\mathrm{H}$, Yang $\mathrm{S}$, Yang $\mathrm{Y}$, Yuan $\mathrm{SX}$, Wu FQ, Wang LL, et al. Epigenetically silenced long noncoding-SRHC promotes proliferation of hepatocellular carcinoma. J Cancer Res Clin Oncol. (2015) 141:1195203. doi: 10.1007/s00432-014-1871-4

113. Cao LQ, Yang XW, Chen YB, Zhang DW, Jiang XF, Xue $P$. Exosomal miR-21 regulates the TETs/PTENp1/PTEN pathway to promote hepatocellular carcinoma growth. Mol Cancer. (2019) 18:148. doi: 10.1186/s12943-019-1075-2

114. Rong D, Sun H, Li Z, Liu S, Dong C, Fu K, et al. An emerging function of circRNA-miRNAs-mRNA axis in human diseases. Oncotarget. (2017) 8:73271-81. doi: 10.18632/oncotarget.19154

115. Xu H, Wang C, Song H, Xu Y, Ji G. RNA-Seq profiling of circular RNAs in human colorectal cancer liver metastasis and the potential biomarkers. Mol Cancer. (2019) 18:8. doi: 10.1186/s12943-018-0932-8

116. Wu C, Deng L, Zhuo H, Chen X, Tan Z, Han S, et al. Circulating circRNA predicting the occurrence of hepatocellular carcinoma in patients with HBV infection. J Cell Mol Med. (2020) 24:10216-22. doi: 10.1111/jcmm. 15635

117. Wu Y, Zhao T, Deng R, Xia X, Li B, Wang X, et al. study of differential circRNA and IncRNA expressions in COVID-19-infected peripheral blood. Sci Rep. (2021) 11:7991. doi: 10.1038/s41598-021-86134-0

118. Kristensen LS, Andersen MS, Stagsted LVW, Ebbesen KK, Hansen TB, Kjems J. The biogenesis, biology and characterization of circular RNAs. Nat Rev Genet. (2019) 20:675-91. doi: 10.1038/s41576-019-0158-7

119. Wang M, Yang Y, Yang J, Yang J, Han S. circ_KIAA1429 accelerates hepatocellular carcinoma advancement through the mechanism of m(6)AYTHDF3-Zeb1. Life Sci. (2020) 257:118082. doi: 10.1016/j.lfs.2020.118082

120. Huang XY, Zhang PF, Wei CY, Peng R, Lu JC, Gao C, et al. Circular RNA circMET drives immunosuppression and anti-PD1 therapy resistance in hepatocellular carcinoma via the miR-30-5p/snail/DPP4 axis. Mol Cancer. (2020) 19:92. doi: 10.1186/s12943-020-01213-6

121. Wang Y, Jiang L, Ji X, Yang B, Zhang Y, Fu XD. Hepatitis B viral RNA directly mediates down-regulation of the tumor suppressor microRNA miR-15a/miR-16-1 in hepatocytes. I Biol Chem. (2013) 288:1848493. doi: 10.1074/jbc.M113.458158

122. Lujambio A, Lowe SW. The microcosmos of cancer. Nature. (2012) 482:34755. doi: 10.1038/nature10888

123. Zhou J, Yu L, Gao X, Hu J, Wang J, Dai Z, et al. Plasma microRNA panel to diagnose hepatitis B virus-related hepatocellular carcinoma. J Clin Oncol. (2011) 29:4781-8. doi: 10.1200/JCO.2011.38.2697

124. St Laurent G, Wahlestedt C, Kapranov P. The landscape of long noncoding RNA classification. Trends Genet. (2015) 31:239-51. doi: 10.1016/j.tig.2015.03.007

125. Bi HQ, Li ZH, Zhang H. Long noncoding RNA HAND2-AS1 reduced the viability of hepatocellular carcinoma via targeting microRNA-300/SOCS5 axis. Hepatobiliary Pancreat Dis Int. (2020) 19:567-74. doi: 10.1016/j.hbpd.2020.02.011

126. Tang W, Fu K, Sun H, Rong D, Wang H, Cao H. CircRNA microarray profiling identifies a novel circulating biomarker for detection of gastric cancer. Mol Cancer. (2018) 17:137. doi: 10.1186/s12943-018-0888-8

127. Chen L, Nan A, Zhang N, Jia Y, Li X, Ling Y, et al. Circular RNA 100146 functions as an oncogene through direct binding to miR-361$3 p$ and miR-615-5p in non-small cell lung cancer. Mol Cancer. (2019) 18:13. doi: 10.1186/s12943-019-0943-0

128. Zhang X, Zhou H, Jing W, Luo P, Qiu S, Liu X, et al. The circular RNA hsa_circ_0001445 regulates the proliferation and migration of hepatocellular carcinoma and may serve as a diagnostic biomarker. Dis Markers. (2018) 2018:3073467. doi: 10.1155/2018/3073467

129. Zhang X, Xu Y, Qian Z, Zheng W, Wu Q, Chen Y, et al. circRNA_104075 stimulates YAP-dependent tumorigenesis through the regulation of HNF4a and may serve as a diagnostic marker in hepatocellular carcinoma. Cell Death Dis. (2018) 9:1091. doi: 10.1038/s41419-018-1132-6 
130. Sukowati CHC, Cabral LKD, Tiribelli C, Pascut D. Circulating long and circular noncoding RNA as non-invasive diagnostic tools of hepatocellular carcinoma. Biomedicines. (2021) 9:90. doi: 10.3390/biomedicines 9010090

131. Li Y, Zheng Q, Bao C, Li S, Guo W, Zhao J, et al. Circular RNA is enriched and stable in exosomes: a promising biomarker for cancer diagnosis. Cell Res. (2015) 25:981-4. doi: 10.1038/cr.2015.82

132. Wang G, Liu W, Zou Y, Wang G, Deng Y, Luo J, et al. Three isoforms of exosomal circPTGR1 promote hepatocellular carcinoma metastasis via the miR449a-MET pathway. EBioMedicine. (2019) 40:43245. doi: $10.1016 /$ j.ebiom.2018.12.062

133. Chen W, Quan Y, Fan S, Wang H, Liang J, Huang L, et al. Exosome-transmitted circular RNA hsa_circ_0051443 suppresses hepatocellular carcinoma progression. Cancer Lett. (2020) 475:119-28. doi: 10.1016/j.canlet.2020.01.022

134. Larance M, Lamond AI. Multidimensional proteomics for cell biology. Nat Rev Mol Cell Biol. (2015) 16:269-80. doi: 10.1038/nrm3970

135. Ferrin G, Aguilar-Melero P, Rodriguez-Peralvarez M, Montero-Alvarez JL, de la Mata M. Biomarkers for hepatocellular carcinoma: diagnostic and therapeutic utility. Hepat Med. (2015) 7:1-10. doi: 10.2147/HMER.S50161

136. Sun Z, Liu X, Wu D, Gao H, Jiang J, Yang Y, et al. Circulating proteomic panels for diagnosis and risk stratification of acute-on-chronic liver failure in patients with viral hepatitis B. Theranostics. (2019) 9:120014. doi: 10.7150/thno.31991

137. Zhao Y, Li Y, Liu W, Xing S, Wang D, Chen J, et al. Identification of noninvasive diagnostic biomarkers for hepatocellular carcinoma by urinary proteomics. J Proteomics. (2020) 225:103780. doi: 10.1016/j.jprot.2020.103780

138. Wiese S, Reidegeld KA, Meyer HE, Warscheid B. Protein labeling by iTRAQ: a new tool for quantitative mass spectrometry in proteome research. Proteomics. (2007) 7:340-50. doi: 10.1002/pmic.200600422

139. Yan LB, Yu YJ, Zhang QB, Tang XQ, Bai L, Huang F, et al. Identification of p90 ribosomal S6 kinase 2 as a novel host protein in HBx augmenting HBV replication by iTRAQ-based quantitative comparative proteomics. Proteomics Clin Appl. (2018) 12:e1700090. doi: 10.1002/prca.2017 00090

140. Liu F, Seto WK, Wong DK, Huang FY, Cheung KS, Mak LY, et al. Plasma fibronectin levels identified via quantitative proteomics profiling predicts hepatitis B surface antigen seroclearance in chronic hepatitis B.J Infect Dis. (2019) 220:940-50. doi: 10.1093/infdis/jiz223

141. Zuo T, Chen P, Jing S, Zhang T, Chang L, Xu F, et al. Quantitative proteomics reveals the development of HBV-associated glomerulonephritis triggered by the downregulation of SLC7A7. J Proteome Res. (2020) 19:155664. doi: 10.1021/acs.jproteome.9b00799

142. Wu B, Shang H, Liu J, Liang X, Yuan Y, Chen Y, et al. Quantitative proteomics analysis of FFPE tumor samples reveals the influences of NET-1 siRNA nanoparticles and sonodynamic therapy on tetraspanin protein involved in HCC. Front Mol Biosci. (2021) 8:678444. doi: 10.3389/fmolb.2021.678444

143. Xu Y, Rong J, Duan S, Chen C, Li Y, Peng B, et al. High expression of GNA13 is associated with poor prognosis in hepatocellular carcinoma. Sci Rep. (2016) 6:35948. doi: 10.1038/srep35948

144. Zhang Y, Yao J, Huan L, Lian J, Bao C, Li Y, et al. GNAI3 inhibits tumor cell migration and invasion and is post-transcriptionally regulated by miR-222 in hepatocellular carcinoma. Cancer Lett. (2015) 356:97884. doi: $10.1016 /$ j.canlet.2014.11.013

145. Yuan S, Tanzeel Y, Tian X, Zheng D, Wajeeha N, Xu J. et al. Global analysis of HBV-mediated host proteome and ubiquitylome change in HepG2215 human hepatoblastoma cell line. Cell Biosci. (2021) 11:75. doi: 10.1186/s13578-021-00588-3

146. Song G, Zhu X, Xuan Z, Zhao L, Dong H, Chen J, et al. Hypermethylation of GNA14 and its tumor-suppressive role in hepatitis B virus-related hepatocellular carcinoma. Theranostics. (2021) 11:2318-33. doi: 10.7150/thno.48739

147. Wu H, Wei L, Fan F, Ji S, Zhang S, Geng J, et al. Integration of Hippo signalling and the unfolded protein response to restrain liver overgrowth and tumorigenesis. Nat Commun. (2015) 6:6239. doi: 10.1038/ncomms7239

148. Zhang X, Ding X, Marshall RS, Paez-Valencia J, Lacey P, Vierstra RD, et al. Reticulon proteins modulate autophagy of the endoplasmic reticulum in maize endosperm. Elife. (2020) 9:e51918. doi: 10.7554/eLife.51918
149. Song S, Shi Y, Wu W, Wu H, Chang L, Peng P, et al. Reticulon 3-mediated Chk2/p53 activation suppresses hepatocellular carcinogenesis and is blocked by hepatitis B virus. Gut. (2020). doi: 10.1136/gutjnl-2020-321386

150. Yuan S, Liao G, Zhang M, Zhu Y, Wang K, Xiao W, et al. Translatomic profiling reveals novel self-restricting virus-host interactions during HBV infection. J Hepatol. (2021) 75:74-85. doi: 10.1016/j.jhep.2021.02.009

151. Gerstberger S, Hafner M, Tuschl T. A census of human RNA-binding proteins. Nat Rev Genet. (2014) 15:829-45. doi: 10.1038/nrg3813

152. Needham EJ, Parker BL, Burykin T, James DE, Humphrey SJ. Illuminating the dark phosphoproteome. Sci Signal. (2019) 12:eaau8645. doi: 10.1126/scisignal.aau8645

153. Lubyová B, Weber J. Posttranslational modifications of HBV core protein. Acta Virol. (2020) 64:177-86. doi: 10.4149/av_2020_207

154. Chabrolles H, Auclair H, Vegna S, Lahlali T, Pons C, Michelet M, et al. Hepatitis B virus core protein nuclear interactome identifies SRSF10 as a host RNA-binding protein restricting HBV RNA production. PLoS Pathog. (2020) 16:e1008593. doi: 10.1371/journal.ppat.1008593

155. Ren L, Li C, Wang Y, Teng Y, Sun H, Xing B, et al. In vivo phosphoproteome analysis reveals kinome reprogramming in hepatocellular carcinoma. Mol Cell Proteomics. (2018) 17:1067-83. doi: 10.1074/mcp.RA117.000421

156. Hu J, Gao Q, Yang Y, Xia J, Zhang W, Chen Y, et al. Hexosamine biosynthetic pathway promotes the antiviral activity of SAMHD1 by enhancing O-GlcNAc transferase-mediated protein O-GlcNAcylation. Theranostics. (2021) 11:805-23. doi: 10.7150/thno.50230

157. Zhang S, Cao X, Gao Q, Liu Y. Protein glycosylation in viral hepatitis-related HCC: characterization of heterogeneity, biological roles, and clinical implications. Cancer Lett. (2017) 406:64-70. doi: 10.1016/j.canlet.2017.07.026

158. Zhang S, Cao X, Liu C, Li W, Zeng W, Li B, et al. N-glycopeptide signatures of IgA2 in serum from patients with hepatitis B virus-related liver diseases. Mol Cell Proteomics. (2019) 18:2262-72. doi: 10.1074/mcp.RA119.001722

159. Chen K, Liu J, Liu S, Xia M, Zhang X, Han D, et al. Methyltransferase SETD2mediated methylation of STAT1 is critical for interferon antiviral activity. Cell. (2017) 170:492-506.e14. doi: 10.1016/j.cell.2017.06.042

160. Zhang F, Wang Y, Chen G, Li Z, Xing X, Putz-Bankuti C, et al. Growing human hepatocellular tumors undergo a global metabolic reprogramming. Cancers (Basel). (2021) 13:1980. doi: 10.3390/cancers13081980

161. Johnson CH, Ivanisevic J, Siuzdak G. Metabolomics: beyond biomarkers and towards mechanisms. Nat Rev Mol Cell Biol. (2016) 17:4519. doi: 10.1038/nrm.2016.25

162. Zhang A, Sun H, Wang P, Han Y, Wang X. Recent and potential developments of biofluid analyses in metabolomics. J Proteomics. (2012) 75:1079-88. doi: 10.1016/j.jprot.2011.10.027

163. Colli A, Fraquelli M, Casazza G, Massironi S, Colucci A, Conte D, et al. Accuracy of ultrasonography, spiral CT, magnetic resonance, and alphafetoprotein in diagnosing hepatocellular carcinoma: a systematic review. Am J Gastroenterol. (2006) 101:513-23. doi: 10.1111/j.1572-0241.2006.00467.x

164. Embade N, Millet O. Molecular determinants of chronic liver disease as studied by NMR-metabolomics. Curr Top Med Chem. (2017) 17:275266. doi: 10.2174/1568026617666170707124539

165. Beckonert O, Keun HC, Ebbels TM, Bundy J, Holmes E, Lindon JC, et al. Metabolic profiling, metabolomic and metabonomic procedures for NMR spectroscopy of urine, plasma, serum and tissue extracts. Nat Protoc. (2007) 2:2692-703. doi: 10.1038/nprot.2007.376

166. Chen JJ, Liu Z, Fan SH, Yang DY, Zheng P, Shao WH, et al. Combined application of NMR- and GC-MS-based metabonomics yields a superior urinary biomarker panel for bipolar disorder. Sci Rep. (2014) 4:5855. doi: 10.1038/srep05855

167. Huang Q, Tan Y, Yin P, Ye G, Gao P, Lu X, et al. Metabolic characterization of hepatocellular carcinoma using nontargeted tissue metabolomics. Cancer Res. (2013) 73:4992-5002. doi: 10.1158/0008-5472.CAN-13-0308

168. Arakawa Y, Moriyama M, Arakawa Y. Liver cirrhosis and metabolism (sugar, protein, fat and trace elements). Hepatol Res. (2004) 30S:4658. doi: 10.1016/j.hepres.2004.10.009

169. Nishikawa T, Bellance N, Damm A, Bing H, Zhu Z, Handa K, et al. A switch in the source of ATP production and a loss in capacity to perform glycolysis are hallmarks of hepatocyte failure in advance liver disease. J Hepatol. (2014) 60:1203-11. doi: 10.1016/j.jhep.2014.02.014 
170. Gatenby RA, Gillies RJ. Why do cancers have high aerobic glycolysis? Nat Rev Cancer. (2004) 4:891-9. doi: 10.1038/nrc1478

171. Gao R, Cheng J, Fan C, Shi X, Cao Y, Sun B, et al. Serum metabolomics to identify the liver disease-specific biomarkers for the progression of hepatitis to hepatocellular carcinoma. Sci Rep. (2015) 5:18175. doi: 10.1038/srep18175

172. Baniasadi H, Gowda GA, Gu H, Zeng A, Zhuang S, Skill N, et al. Targeted metabolic profiling of hepatocellular carcinoma and hepatitis C using LCMS/MS. Electrophoresis. (2013) 34:2910-7. doi: 10.1002/elps.201300029

173. Beyoglu D, Imbeaud S, Maurhofer O, Bioulac-Sage P, Zucman-Rossi J, Dufour JF, et al. Tissue metabolomics of hepatocellular carcinoma: tumor energy metabolism and the role of transcriptomic classification. Hepatology. (2013) 58:229-38. doi: 10.1002/hep.26350

174. Dennis EA, Norris PC. Eicosanoid storm in infection and inflammation. Nat Rev Immunol. (2015) 15:511-23. doi: 10.1038/nri3859

175. Vander Heiden MG. Targeting cancer metabolism: a therapeutic window opens. Nat Rev Drug Discov. (2011) 10:671-84. doi: 10.1038/nrd3504

176. Xie Q, Fan F, Wei W, Liu Y, Xu Z, Zhai L, et al. Multi-omics analyses reveal metabolic alterations regulated by hepatitis B virus core protein in hepatocellular carcinoma cells. Sci Rep. (2017) 7:41089. doi: 10.1038/srep41089

177. Guo Y, Kang W, Lei X, Li Y, Xiang A, Liu Y, et al. Hepatitis B viral core protein disrupts human host gene expression by binding to promoter regions. $B M C$ Genomics. (2012) 13:563. doi: 10.1186/1471-2164-13-563

178. Zhu Y, Jin Y, Cai X, Bai X, Chen M, Chen T, et al. Hepatitis B virus core protein variations differ in tumor and adjacent nontumor tissues from patients with hepatocellular carcinoma. Intervirology. (2012) 55:2935. doi: $10.1159 / 000322832$

179. Zhang Y, Ren Y, Wu Y, Zhao B, Qiu L, Li X, et al. The L60V variation in hepatitis B virus core protein elicits new epitope-specific cytotoxic T lymphocytes and enhances viral replication. J Virol. (2013) 87:807584. doi: 10.1128/JVI.00577-13

180. Song M, Sun Y, Tian J, He W, Xu G, Jing Z, et al. Silencing retinoid X receptor alpha expression enhances early-stage hepatitis $\mathrm{B}$ virus infection in cell cultures. J Virol. (2018) 92:e01771-17. doi: 10.1128/JVI.01771-17

181. Philips CA, Augustine P, Yerol PK, Ramesh GN, Ahamed R, Rajesh S, et al. Modulating the intestinal microbiota: therapeutic opportunities in liver disease. J Clin Transl Hepatol. (2020) 8:87-99. doi: 10.14218/JCTH.2019.00035
182. Compare D, Coccoli P, Rocco A, Nardone OM, De Maria S, Cartenì $\mathrm{M}$, et al. Gut-liver axis: the impact of gut microbiota on non alcoholic fatty liver disease. Nutr Metab Cardiovasc Dis. (2012) 22:471-6. doi: 10.1016/j.numecd.2012.02.007

183. Liu Q, Li F, Zhuang Y, Xu J, Wang J, Mao X, et al. Alteration in gut microbiota associated with hepatitis B and non-hepatitis virus related hepatocellular carcinoma. Gut Pathog. (2019) 11:1. doi: 10.1186/s13099-0180281-6

184. Zheng R, Wang G, Pang Z, Ran N, Gu Y, Guan X, et al. Liver cirrhosis contributes to the disorder of gut microbiota in patients with hepatocellular carcinoma. Cancer Med. (2020) 9:4232-50. doi: 10.1002/cam4. 3045

185. Chakladar J, Wong LM, Kuo SZ, Li WT, Yu MA, Chang EY, et al. The liver microbiome is implicated in cancer prognosis and modulated by alcohol and hepatitis B. Cancers (Basel). (2020) 12:1642. doi: 10.3390/cancers120 61642

186. Zhang E, Zhang M, Shi C, Sun L, Shan L, Zhang H, et al. An overview of advances in multi-omics analysis in prostate cancer. Life Sci. (2020) 260:118376. doi: 10.1016/j.lfs.2020.118376

Conflict of Interest: The authors declare that the research was conducted in the absence of any commercial or financial relationships that could be construed as a potential conflict of interest.

Publisher's Note: All claims expressed in this article are solely those of the authors and do not necessarily represent those of their affiliated organizations, or those of the publisher, the editors and the reviewers. Any product that may be evaluated in this article, or claim that may be made by its manufacturer, is not guaranteed or endorsed by the publisher.

Copyright $\odot 2021$ Cui, Li, Jiang, Wu, Xie and Wu. This is an open-access article distributed under the terms of the Creative Commons Attribution License (CC BY). The use, distribution or reproduction in other forums is permitted, provided the original author(s) and the copyright owner(s) are credited and that the original publication in this journal is cited, in accordance with accepted academic practice. No use, distribution or reproduction is permitted which does not comply with these terms. 